\title{
EL ODS 16 EN LA AGENDA 2030: DE LA INDEFINICIÓN A ALGUNAS PROPUESTAS (IUSFILOSÓFICAS) PARA SU CONCRECIÓN
}

\author{
SDG 16 IN THE 2030 AGENDA: FROM INDEFINICTION TO SOME PROPOSALS \\ (PHILOSOPHICAL IUS) FOR THEIR CONCRETION
}

\author{
Nuria Belloso Martin ${ }^{1}$
}

\section{RESUMEN}

En este estudio se analiza el Objetivo 16 de la Agenda 2030 para el Desarrollo Sostenible. El ODS 16 se propone la consecución de doce metas que pueden aglutinarse en tres submetas: promoción de "sociedades pacíficas", "facilitar el acceso a la justicia para todos" y "promover instituciones sólidas e inclusivas". La introducción de este Objetivo es uno de los aspectos más novedosos de la Agenda a la vez que también resulta ser uno de los ODS más amplios e indefinidos. Se aportarán algunas propuestas en aras de una mejor concreción. Se prestará especial atención a la meta de la consecución de la paz, para lo que se indagará en las bases filosóficas de la cultura de la paz. El perfil esencialmente político de este ODS requiere la colaboración de Gobiernos y sociedad civil para su implementación.

Palabras clave: indefinición, ODS, paz, acceso a la justicia, transparencia

\begin{abstract}
In this study is analyzed the Objective 16 of the 2030 Agenda for Sustainable Development. The ODS 16 proposes the achievement of twelve goals that can be grouped into three sub-goals: promotion of "peaceful societies", "facilitating access to justice for all" and promoting "solid and inclusive institutions". The introduction of this Objective is one of the most novel aspects of the Agenda while also being one of the broadest and most indefinite SDGs. Some proposals will be provided for better realization. Special attention will be given to the goal of achieving peace, for which it will be investigated in the philosophical foundations of the culture of peace. The essentially political profile of this SDG requires the collaboration of governments and civil society for its implementation.
\end{abstract}

Keywords: undefined, ODS, peace, access to justice, transparency

\section{INTRODUCCIÓN}

\footnotetext{
${ }^{1}$ Nuria Belloso Martín es Profesora Titular de Filosofía del Derecho en la Facultad de Derecho de la Universidad de Burgos (España). Es Coordinadora del Programa de Doctorado del Departamento de Derecho Público "Sociedad plural y nuevos retos del Derecho". Es Directora del Curso de Especialista Universitario en Mediación Familiar. Colabora en Cursos de Mestrado y Doctorado en diversas Universidades brasileñas. Participa en varios Programas de Investigación -CNpQ. Universidad de Burgos - Espanha. ORCID: https://orcid.org/0000-00015681-778X Lattes: http://lattes.cnpq.br/4113854581352857 E-mail: nubelloso@gmail.com
} 
En septiembre del año 2015, en la cumbre de Naciones Unidas, mediante la Resolución 70/1 de la Asamblea General de Naciones Unidas, titulada "Transformar nuestro mundo: la Agenda 2030 para el Desarrollo Sostenible”, 193 países aprobaron los 17 objetivos de Desarrollo Sostenible (ODS) para toda la Comunidad Internacional. ${ }^{2}$ Los 193 Estados miembros de la ONU que han adoptado los 17 ODS lo han hecho como fines hacia los que orientar no únicamente sus políticas públicas sino también la actuación del sector privado, la sociedad civil y los individuos. Este diseño de objetivos, metas e indicadores puede situarse en el ámbito del llamado soft law, sin efectos jurídicos directos pero visible influencia en las políticas y en la legislación doméstica. Los 17 ODS constituyen "un plan de acción a favor de las personas, el planeta y la prosperidad" (Naciones Unidas) (Mesa: 2017, p.17). Entre esos objetivos se pueden citar: el fin de la pobreza (objetivo 1), el hambre cero (objetivo 2), la salud y bienestar (objetivo 3), la educación de calidad (objetivo 4), la igualdad de género (objetivo 5), la reducción de las desigualdades (objetivo 10) y la paz, justicia e instituciones sólidas (objetivo 16).

La Agenda 2030 refleja un mundo más transnacional y con problemas globales apremiantes, donde el poder político sigue estando descentralizado en Estados soberanos reacios a asumir compromisos vinculantes, y con un creciente número de actores no gubernamentales y privados más influyentes. Es un mundo más multipolar, multicéntrico y post-occidental, y con una creciente heterogeneidad en cuanto a visiones y valores, lo que ya permite aventurar los desiguales resultados que habrá en la implantación de los ODS. Quizás por ello, la Agenda 2030 se ha convertido finalmente en una agregación de temas, sin prioridades claras y que no permite saber el nivel en el que cada meta debe cumplirse. No se pretende establecer una comparativa entre el "Norte y el Sur global" pero sí debe dejarse constancia de que la aplicación de la Agenda a contextos geográficos y políticos tan diversos (Europa, Asia, África, Latinoamérica) resulta compleja ya que el punto de partida en cada contexto es muy diferente.

El ODS 16 resulta especialmente difícil de concretar. Es el que tiene el número más elevado de metas - concretamente, doce- y la menor precisión y claridad respecto a los medios para su implementación. La propia gestación del ODS 16 no estuvo exenta de discusiones en

\footnotetext{
${ }^{2}$ Transformar nuestro mundo: Agenda 2030 para el Desarrollo Sostenible. Resolución aprobada por la Asamblea General de Naciones Unidas el 25 de septiembre de 2015 . A/RES/70/1. http://www.un.org/sustainabledevelopment/es/2015/09/la-asamblea-general-adopta-la-agenda-2030-para-eldesarrollo-sostenible/.
} 
cuanto a si convenía o no incluirlo en la Agenda. Finalmente, la dimensión esencialmente política que acompaña al ODS 16 ha hecho que se le haya configurado el ODS 16 como la cuarta "dimensión" del desarrollo sostenible, equiparable a las otras tres "dimensiones" económica, social y ambiental - ya contempladas en el Documento final de Rio+20, en 2012 (Naciones Unidas 2014).

Tomando como punto de partida la "Declaración del Milenio" y sus Objetivos de Desarrollo del Milenio (ODM) , adoptada por la Asamblea General en el año $200{ }^{3}$-donde se reconocía que la paz y la seguridad humana eran condición necesaria para el desarrollo y sin que se hubiera incluido ninguna meta en esta materia- se tenía la esperanza de que la Agenda 2030 hubiera incorporado las enseñanzas de los últimos veinticinco años en cuanto al complejo nexo entre paz, seguridad y desarrollo. Sin embargo, del examen del ODS 16 se podrá observar que sus metas resultan excesivamente vagas e indefinidas. Además, aunque se pretendan dejar atrás las tradicionales agendas Norte-Sur para centrarse en cometidos más global y transnacionales, ello no impide reconocer que aún hay marcadas asimetrías en los niveles de desarrollo entre los países avanzados y en desarrollo, y en estos últimos, entre los de renta media y los más pobres. A partir de esas distintas capacidades, cada parte habrá de asumir responsabilidades diferenciadas ante esa Agenda (Sanahuja: 2018, p. 29).

Puesto que se ha encargado a los Gobiernos de los diversos Estados que elaboren estrategias para implementar la Agenda 2030 y puesto que el ODS 16 se plantea reducir significativamente toda expresión de violencia y de corrupción a través de la creación de estructuras institucionales que fomenten la participación social en todos sus ámbitos, en este estudio se ofrecerán unas reflexiones sobre el ODS 16 incidiendo en su perfil indefinido seguramente derivado de su carácter marcadamente político. A partir de ahí, se analizarán dos cuestiones: en primer lugar, la submeta de sociedades pacíficas, no violentas e inclusivas para lo que se incidirá en la necesidad de educar en una cultura de la paz (lo que puede hacerse impulsando procedimientos como la mediación y formulando iniciativas que enseñen a prevenir la violencia y a gestionar las controversias), facilitando no sólo el acceso de todos a la justicia sino a un modelo de "justicia integral", capaz de ofrecer el procedimiento más adecuado de gestión de conflictos según el tipo de conflicto de que se trate. En segundo lugar, se examinará

\footnotetext{
${ }^{3}$ A diferencia de los Objetivos del Milenio (2000-2015), que se enfocaban en el progreso de los países pobres, los ODS son universales: todos los países, incluidos los más prósperos, tienen que cumplirlos pues que sean ricos no significa que no tengan problemas internos — como la desigualdad o la violencia de género-y responsabilidades, sobre todo respecto a la lucha contra el cambio climático y la ayuda al desarrollo de las naciones menos avanzadas. Boletín de Biblioteca Depositaria de las Naciones Unidas (ONUBIB) (2018). año 4, n³, Universitat de Valencia, p.30.
} 
cómo los Gobiernos de los distintos ámbitos (europeo, nacional, autonómico y local), en cuanto responsables de la implementación de la Agenda 2030, han impulsado el ODS 16 a través de diferentes acciones y mecanismos. A pesar de los logros conseguidos, aún queda mucho por hacer en los próximos diez años.

\section{EL OBJETIVO 16 EN LA AGENDA 2030: UN EJEMPLO DE INDEFINICIÓN}

El Objetivo 16 de la Agenda 2030 -cuya denominación abreviada es Paz, Justicia e Instituciones sólidas- propone lo siguiente:

Objetivo 16. Promover sociedades pacíficas e inclusivas para el desarrollo sostenible, facilitar el acceso a la justicia para todos y construir a todos los niveles instituciones eficaces $e$ inclusivas que rindan cuentas. ${ }^{4}$ (La cursiva es nuestra)

Como puede deducirse del enunciado del ODS 16, se plantean tres importantes retos: i) Promover sociedades pacíficas e inclusivas para el desarrollo sostenible (Izquierdo Ramírez y Ortega Camarero: 2020); b) facilitar el acceso a la justicia para todos; y c) construir a todos los niveles instituciones eficaces e inclusivas que rindan cuentas. A su vez, estos tres retos se proyectan en diez metas:

16.1 Reducir significativamente todas las formas de violencia y las correspondientes tasas de mortalidad en todo el mundo

16.2 Poner fin al maltrato, la explotación, la trata y todas las formas de violencia y tortura contra los niños.

16.3 Promover el estado de derecho en los planos nacional e internacional y garantizar la igualdad de acceso a la justicia para todos.

16.4 De aquí a 2030, reducir significativamente las corrientes financieras y de armas ilícitas, fortalecer la recuperación y devolución de los activos robados y luchar contra todas las formas de delincuencia organizada.

16.5 Reducir considerablemente la corrupción y el soborno en todas sus formas. 16.6 Crear a todos los niveles instituciones eficaces y transparentes que rindan cuentas.

16.7 Garantizar la adopción en todos los niveles de decisiones inclusivas, participativas y representativas que respondan a las necesidades.

16.8 Ampliar y fortalecer la participación de los países en desarrollo en las instituciones de gobernanza mundial.

16.9 De aquí a 2030, proporcionar acceso a una identidad jurídica para todos, en particular mediante el registro de nacimientos.

16.10 Garantizar el acceso público a la información y proteger las libertades fundamentales, de conformidad con las leyes nacionales y los acuerdos internacionales.

16.a Fortalecer las instituciones nacionales pertinentes, incluso mediante la cooperación internacional, para crear a todos los niveles, particularmente en los

\footnotetext{
4 A/Res/70/1, Transformar nuestro mundo: la Agenda 2030 para el Desarrollo sostenible, p.16.
} 
países en desarrollo, la capacidad de prevenir la violencia y combatir el terrorismo y la delincuencia.

16.b Promover y aplicar leyes y políticas no discriminatorias en favor del desarrollo sostenible.

Tal y como establece el Plan de Acción para la implementación de la Agenda 2030. Hacia una Agenda Española de Desarrollo Sostenible, el ODS 16 busca “conseguir la justicia y su corolario, la paz, así como facilitar el derecho fundamental de acceso a la justicia para los más desfavorecidos, reforzar la lucha contra el narcotráfico, la corrupción y la delincuencia organizada transnacional, y aplicar las nuevas tecnologías a la administración de justicia de forma que esta sea más rápida, ágil y eficaz y cumpla por tanto con su doble labor de castigar al culpable y contribuir a reparar el daño causado sin demoras". ${ }^{5}$ Y continúa el Plan explicando que los retos actuales planteados por la pobreza, el hambre, la disminución de los recursos naturales, la escasez de agua, la desigualdad social, la degradación ambiental, las enfermedades, la corrupción, el racismo y la xenofobia, entre otros factores, suponen un desafío para la paz y generan un terreno fértil para el surgimiento de conflictos. El desarrollo sostenible contribuye de manera decisiva a disipar y eliminar estas causas de conflicto, además de sentar las bases para una paz duradera. La paz, a su vez, consolida las condiciones requeridas para el desarrollo sostenible y moviliza los recursos necesarios que permiten a las sociedades desarrollarse y prosperar. Las ciudades y los pueblos son el hogar común de millones de personas, y las instituciones que las gobiernan pueden tener un papel clave en la consecución de dichos objetivos.

Ni la Agenda en su conjunto ni tampoco el ODS 16 en concreto han conseguido escapar a las objeciones. Así, con respecto a la Agenda, se pone en cuestión que la definición de metas globales en Naciones Unidas sea el resultado de un proceso deliberativo y decisorio recurriendo a la teoría habermasiana de la acción comunicativa y de la ética del discurso-. Es decir, existe el temor de que las asimetrías de poder del sistema internacional generen un discurso universalista que se impondría sobre éticas particularistas y/o sobre las posibles visiones etnocéntricas de Occidente respecto al desarrollo humano (Sanahuja: 2018, p. 32).

Por otro lado, el ODS 16 también ha recibido varias críticas tales como la indefinición y amplitud de sus metas; su valor esencialmente ético y de mera recomendación - y no jurídico y obligatorio-; su aplicación a contextos democráticos de diferente consolidación lo que hará que los procesos de implantación de sus metas admita una gradación muy diferenciada; A ello

\footnotetext{
${ }^{5}$ Plan de Acción para la implementación de la Agenda 2030. Hacia una Agenda Española de Desarrollo Sostenible. Gobierno de España. (22 de junio de 2018), pp.61-63. www.exteriores.gob.es/...PLAN\%20DE\%20ACCION\%20PARA\%20LA\%20IMPLEME..
} 
hay que añadir que los indicadores del seguimiento de la implantación de las metas resultan excesivamente específicos por una lado y amplios (a nivel supranacional) por otro, lo cual dificulta su seguimiento ya que o bien no se han elaborado las estadísticas pertinentes o bien esas estadísticas abarcan un espectro más amplio que el que se pretende rastrear (son de ámbito nacional o autonómico y no local). ${ }^{6}$ Esta última crítica es aplicable a la mayoría de las 169 metas previstas ya que son explicitadas mediante un número muy elevado de indicadores de progreso, y no siempre existen fuentes de datos fiables y/o comparables, lo que puede desalentar su cumplimiento. El desafío estadístico de los ODS es enorme. Incluso los países avanzados están teniendo dificultades, y para los países más pobres o emergentes, el reto es de tal magnitud que cabe pronosticar que sin apoyo adecuado no serán capaces de establecer cuál es el punto de partida y mucho menos de monitorizar sus avances o retrocesos. Conviene analizar estas cuatro críticas para que se entiendan debidamente.

Con respecto a su indefinición, la amalgama de metas contenidas en el ODS 16 hace que pierda fuerza el propio Objetivo, ya que se fragmenta en cuestiones tan variadas como el registro de nacimientos hasta combatir el terrorismo pasando por reducir significativamente las corrientes financieras y de armas ilícitas. Son metas excesivamente genéricas e indefinidas a la vez que sumamente complejas como se pone de manifiesto en la submeta "16.b Promover y aplicar leyes y políticas no discriminatorias en favor del desarrollo sostenible" en las que tiene cabida propuestas de diverso perfil (educativas, políticas, económicas, etc).

En relación a su valor esencialmente ético, existe el peligro de que, en la línea de lo que sucedió con la Declaración Universal de Derechos humanos de 1948, por querer ser tan ambiciosa y amplia abarcando a todos los seres humanos, al no ir acompaña de instrumentos sancionadores, se le atribuyera un valor más ético que jurídico. Por ello, en la redacción del ODS 16, además de los buenos propósitos que pueden deducirse de la terminología empleada (ampliar, promover, fortalecer, reducir) e incluso, a veces con términos más imperativos (crear, garantizar, aplicar leyes, poner fin, etc.) deberían haberse concretado acciones realistas.

\footnotetext{
${ }^{6}$ La medición de los 232 indicadores de la Agenda 2030 de la Organización de las Naciones Unidas (ONU) es una de las claves para verificar el estado del cumplimiento de las 169 metas de los 17 Objetivos de Desarrollo Sostenible (ODS) y, por tanto, de garantía de éxito de la Agenda 2030 a nivel mundial. Sin embargo, estos indicadores deben de ser valorados por cada uno de los países firmantes del acuerdo para que, según sus realidades y prioridades dentro de los ODS, adoptar aquellos que aporten más valor a la Estrategia 2030 de cada país. Los 232 indicadores establecidos por la Asamblea de las Naciones Unidas, se clasifican en tres niveles, de acuerdo a su desarrollo metodológico y la disponibilidad de los datos: a) Nivel II: la metodología y las normas están disponibles, pero los datos no se producen periódicamente por los países; b) Nivel I: la metodología y las normas están disponibles y los datos se producen periódicamente por los países; c) Nivel III: no se dispone de metodología o normas establecidas. Vid. Indicadores de la Agenda 2030. Instituto Nacional de Estadística (INE). https://www.ine.es/dynt3/ODS/es/index.htm
} 
Posiblemente, esta queja no sólo deba atribuirse al ODS 16 sino a la Agenda en su conjunto, ya que al tratarse de una Resolución de Naciones Unidas, por regla general no son vinculantes aunque sí contribuyen a la creación de costumbre internacional (que es una fuente del Derecho) y de prácticas interpretativas de la Carta de la ONU.

En cuanto a su aplicación, las metas del Objetivo 16 -como de cualquier otro de los Objetivos- deben de tomar como punto de partida la realidad del país en el que se inscriban, que variará sustancialmente dependiendo del contexto geográfico que se tome como referencia. Unión Europea, Latinoamérica, Asia o África subsahariana arrojan unos datos muy diferenciados. La promoción de sociedades pacíficas e inclusivas ya de por sí es un reto muy amplio. La paz puede referirse tanto a evitar guerras entre Estados como conflictos interindividuales (homicidios, inseguridad en las calles, población que se siente segura al caminar sola en su zona de residencia, tráfico de armas y tantos otros); Las amenazas de homicidio intencional, la violencia contra los niños, la trata de personas y la violencia sexual, prostitución, maltrato son temas que deben anlizarse para crear sociedades pacíficas e inclusivas. Aunque han disminuido los casos de homicidios y trata de personas en la última década, aún hay miles de personas en mayor riesgo de homicidio intencional en América Latina, el África subsahariana y Asia. Las violaciones de los derechos de los niños mediante la agresión y la violencia sexual siguen persistiendo - agravados en ocasiones por falta de información al respecto y porque no hay datos o estadísticas que así lo constaten-.

Por último, en cuanto a las dificultades para seguir la trazabilidad del nivel de consecución de las doce metas o su nivel de implementación, puede citarse desde la subjetividad que puede acompañar a quien realiza tal labor y que debe de identificar si se han conseguido o no tales metas, a los propios enunciados de los indicadores, muchos de ellos redactados a un nivel internacional o con sentido en otros contextos geográficos pero no en Europa.

Basta hacer referencia a algunos de los indicadores recomendados para llevar a cabo tal seguimiento de la implementación. Por ejemplo, en relación al "Objetivo 16.1.Reducir significativamente todas las formas de violencia y las correspondientes tasas de mortalidad en todo el mundo", no es fácil obtener datos estadísticos sobre ciertos indicadores, bien sea porque la estadística se ha elaborado a nivel macro (a nivel internacional o nacional y no en el ámbito regional o local), o porque algunas informaciones colisionan con la protección de datos. Es el caso de: "Muertes relacionadas con conflictos por cada 100.000 habitantes, desglosadas por sexo, edad y causa"; o sobre la "Proporción de la población que ha sufrido violencia física, psicológica o sexual en los últimos 12 meses”, o sobre Proporción de la población que se siente segura al caminar sola en su zona de residencia”. En otros casos, la información solo podría 
encontrarse en estadísticas que manejan determinados especialistas u operadores jurídicos. Por ejemplo, en el "ODS 16.3. Promover el estado de derecho en los planos nacional e internacional y garantizar la igualdad de acceso a la justicia para todos", conocer la "Proporción de víctimas de violencia en los últimos 12 meses que han notificado su victimización a las autoridades competentes u otros mecanismos de resolución de conflictos reconocidos oficialmente”, es una información de la que sólo suelen disponer los operadores jurídicos responsables. Igualmente sucede en el caso del ODS 16.4 en relación al

Valor total de las corrientes financieras ilícitas entrantes y salientes (en dólares corrientes de los Estados Unidos)" o a la "Proporción de armas incautadas, encontradas o entregadas cuyo origen o contexto ilícitos han sido determinados o establecidos por una autoridad competente, de conformidad con los instrumentos internacionales.

O también en el ODS 16.5 sobre la reducción de la corrupción y de los sobornos, en relación a la

Proporción de personas que han tenido al menos un contacto con un funcionario público y que han pagado un soborno a un funcionario público, o a las que un funcionario público les ha pedido un soborno, durante los últimos 12 meses" y "Proporción de negocios que han tenido al menos un contacto con un funcionario público y que han pagado un soborno a un funcionario público, o a los que un funcionario público les ha pedido un soborno, durante los últimos 12 meses".

Menores dificultades deberían encontrarse para hacer un seguimiento del "ODS 16.6 Crear a todos los niveles instituciones eficaces y transparentes que rindan cuentas", ya que datos tales como "Gastos primarios del gobierno en proporción al presupuesto aprobado originalmente, desglosados por sector (o por códigos presupuestarios o elementos similares)" o del "ODS 16.7 Garantizar la adopción en todos los niveles de decisiones inclusivas, participativas y representativas que respondan a las necesidades", en relación a "Proporciones de plazas (desglosadas por sexo, edad, personas con discapacidad y grupos de población) en las instituciones públicas (asambleas legislativas nacionales y locales, administración pública, poder judicial), en comparación con la distribución nacional”, datos estadísticos todos ellos que, en teoría, deberían ser públicos y accesibles para todos los ciudadanos pero que, en la práctica, son difíciles de rastrear. ${ }^{7}$

\footnotetext{
${ }^{7}$ Las tecnologías innovadoras - como la IA- también pueden desempeñar un papel fundamental para hacer realidad el Objetivo 16 y promover sociedades pacíficas e inclusivas basadas en instituciones sólidas y transparentes. "Esas tecnologías permiten a las personas tener acceso a los procesos de formulación de políticas, entre otras cosas mediante aplicaciones de gobierno electrónico, y les facilitan el acceso a los servicios públicos. La inteligencia artificial puede ayudar a frenar la financiación ilícita, así como la corrupción y la elusión de impuestos, al analizar y denunciar transacciones monetarias sospechosas". Informe del Secretario General (E/2018/66, 21 May 2018). http://undocs.org/es/E/2018/66
} 
Las críticas enunciadas animan a configurar escenarios que hagan viable su progresiva implementación. Partiendo de los tres objetivos nucleares que se contienen en el ODS 16, hay que seguir trabajando en el diseño de unas propuestas viables y realistas para su implementación:

En primer lugar, para lograr sociedades más pacíficas e inclusivas se requiere adoptar medidas tales como:

-Implementación del registro civil de todos los nacimientos, garantizando así el reconocimiento de la personalidad civil

-Lucha contra la violencia en todas sus formas (trata, explotación, homicidios, secuestros)

-Inclusión de personas con discapacidad especial, inmigrantes u otros colectivos, por ejemplo, mediante un sistema educativo inclusivo. ${ }^{8}$

-Cuidar el empoderamiento de los grupos más vulnerables (mujeres, niños, inmigrantes) para lograr su inclusión

-Reglamentaciones más eficaces y transparentes de las instituciones, Administraciones y poderes públicos

- Presupuestos realistas en todas las esferas de poder

-Implementación de una educación en y por la paz

En segundo lugar, el derecho de acceso a la justicia, además de ser el único ODS puesto en expresa correlación con los derechos humanos en toda la Agenda 2030 (Cacho Sánchez: 2019, p.4) es de uno de los derechos humanos esenciales y básicos que permiten el ejercicio de los otros derechos humanos (Quispe Ramón: 2018, p.242) y la consecución de esta meta requiere:

-Adoptar medidas para evitar la corrupción en instituciones y también del Poder Judicial y de las Fuerzas y Cuerpos de Seguridad del Estado

- Aprobación del Plan Justicia 2030, con los objetivos de consolidar los derechos y garantías de los ciudadanos, promover una mayor eficiencia del servicio público y garantizar el acceso a la Justicia en todo el territorio

- Culminar la implantación de la Oficina Judicial y del expediente judicial digital e integrar las diferentes plataformas de gestión procesal

- Aaprobación de la Ley Orgánica de Protección Integral a la Infancia y la Adolescencia frente a la Violencia y la Ley Orgánica del Derecho de Defensa.

-Evitar -o al menos reducir- la proporción de reclusos detenidos sin sentencia.

En tercer lugar, en cuanto a la promoción de instituciones eficaces, transparentes e inclusivas, habría que:

\footnotetext{
-Diseñar una política efectiva de lucha contra la corrupción

-Lucha efectiva contra el soborno -principalmente de funcionarios públicos y políticos-, el robo y la evasión de impuestos
}

\footnotetext{
${ }^{8}$ En varios Centros educativos de Castilla y León se ha iniciado un Plan piloto de atención a la diversidad, en el marco del II Plan de Atención a la Diversidad (2017-2022).

https://www.educa.jcyl.es/dpburgos/es/apebu/inclusion-orientacion-educativa-absentismo. Los denominados "Centros 2030" pretenden dar respuesta a esa diversidad.
} 
-Establecer mecanismos institucionales transparentes, con controles reales y reclamar que los representantes electos rindan cuentas.

-Exigir la garantía del acceso público a la información estableciendo desde Códigos de Buenas prácticas (nivel ético) a obligación de presentación de Memorias anuales (nivel jurídico).

Sin embargo, estas propuestas, aun bienintencionadas, de nuevo nos remiten al ámbito de la generalidad, indefinición y meros propósitos de políticas transformadoras que permitieran su implantación. Un análisis DAFO permitirá apreciar más claramente algunos de los aspectos positivos y negativos del ODS

16:

\begin{tabular}{|c|c|c|}
\hline & POSITIVOS & NEGATIVOS \\
\hline $\begin{array}{l}\mathbf{I} \\
\mathbf{N} \\
\mathbf{T} \\
\mathbf{E} \\
\mathbf{R} \\
\mathbf{N} \\
\mathbf{O} \\
\mathbf{S}\end{array}$ & $\begin{array}{l}\text { Fortalezas } \\
\text { 1.Es un ODS transversal a toda la Agenda } \\
2030 \\
\text { 2.Creación de sinergias con Administraciones } \\
\text { públicas, empresas y sociedad civil } \\
\text { 3. Implantación de sistemas open-doors en la } \\
\text { Administración de Justicia que contemplen la } \\
\text { Mediación como forma complementaria de } \\
\text { resolución de conflictos } \\
\text { 4.Implicación de Colegios Profesionales } \\
\text { (Abogados, Psicólogos), Tribunales y } \\
\text { operadores jurídicos en la consecución de una } \\
\text { justicia para todos } \\
\text { 5.Educación inclusiva: implantación en } \\
\text { centros educativos de planes piloto }\end{array}$ & $\begin{array}{l}\text { Debilidades } \\
\text { 1.ODS } 16 \text { es muy amplio, ambiguo, } \\
\text { genérico y excesivamente ambicioso. Muy } \\
\text { complejo en época de mensajes simples y } \\
\text { breves } \\
\text { 2. Falta de conocimiento de la Agenda y } \\
\text { del ODS } 16 \text { en particular } \\
\text { 3. Escasa implicación de ciudadanos y } \\
\text { responsables } \\
\text { 4. Dificultades (por falta de estadísticas, } \\
\text { por protección de datos) para conocer el } \\
\text { grado de implementación de algunas sus } \\
\text { metas en la ciudad (datos relativas a } \\
\text { internos en centros penitenciarios, } \\
\text { agresiones sexuales, sobornos, } \\
\text { corrupción) } \\
\text { 5. Dificultad a la hora de luchar contra } \\
\text { determinados tipo de delitos que se } \\
\text { realizan en la más absoluta clandestinidad: } \\
\text { explotación, trata, tortura y otros. }\end{array}$ \\
\hline $\begin{array}{l}\mathbf{E} \\
\mathbf{X} \\
\mathbf{T} \\
\mathbf{E} \\
\mathbf{R} \\
\mathbf{N} \\
\mathbf{O} \\
\mathbf{S}\end{array}$ & $\begin{array}{l}\text { Oportunidades } \\
\text { 1.Cualquiera puede verse reflejado en el ODS } \\
\text { 16 (paz, justicia, instituciones sólidas) } \\
\text { 2.Aprovechar la implicación de los educadores } \\
\text { y docentes - de todos los niveles- para formar } \\
\text { en los valores del ODS } \\
\text { 3.Introducción de enlaces de información a los } \\
\text { ciudadanos de sus derechos de acceso a la } \\
\text { justica y turno de oficio en la página web } \\
\text { general de Administraciones e Instituciones } \\
\text { públicas } \\
\text { 4. Aprovechar personal y medios de } \\
\text { comunicación/ publicidad de } \\
\text { Administraciones públicas y empresas para } \\
\text { difundir el ODS16 (incluyendo a todos los } \\
\text { agentes implicados). }\end{array}$ & $\begin{array}{l}\text { Amenazas } \\
\text { 1.Cambios en la política (internacional, } \\
\text { nacional y local) que afecte a su } \\
\text { implementación. } \\
\text { 2. Casi nula vinculación con los derechos } \\
\text { humanos (referencias genéricas en la } \\
\text { Agenda 2030) y que son esenciales en el } \\
\text { ODS 16: paz y justicia. } \\
\text { 3. No realizar las inversiones necesarias } \\
\text { para su consecución } \\
\text { 4.Riesgo de que se incremente la } \\
\text { insatisfacción de los ciudadanos (Justicia, } \\
\text { inclusión) si se incrementa la violencia en } \\
\text { las ciudades o si no se planifican } \\
\text { adecuadamente (falta de medios de } \\
\text { transporte, deslocalización de empresas, } \\
\text { etc.) }\end{array}$ \\
\hline
\end{tabular}


Para elaborar un programa de medidas más concreto y ajustado se requeriría un estudio que ahora excede los límites propuestos en este trabajo. Por ello, nos vamos a centrar en la meta de la paz y de sociedades pacíficas, para no incurrir en el error que denunciamos -es decir, que por querer ser tan ambiciosos, perdernos en una generalidad e indefinición de análisis y de propuestas-.

\subsection{La paz como meta transversal de la Agenda 2030 y eje del ODS 16}

Las metas del ODS 16 ponen de manifiesto el papel nuclear que debería tener el logro de la paz, y ello tanto para la consecución del ODS 16 como para todos los Objetivos de la Agenda 2030. La introducción de este Objetivo es uno de los aspectos más novedosos de los ODS - principalmente si se comparan con los ODM-. El ODS 16 constituye una de las principales innovaciones que suponen los ODS: la aparición de objetivos y metas relativas a la paz, la seguridad, y el "buen gobierno", que por primera vez dotan a las metas globales de un componente explícitamente político, que se sumaría, como elemento transversa y transformador, a las tradicionales dimensiones social, ambiental y económica del desarrollo sostenible (Sanahuja: 2018, p. 28). A la vez, se vincula estrechamente con la consecución del desarrollo sostenible pues sólo en sociedades pacíficas se estará en condiciones de alcanzar otras metas. En el Preámbulo de la Resolución 70/1 se establece que "no puede haber desarrollo sostenible sin paz, ni paz sin desarrollo sostenible": "Paz- Estamos decididos a propiciar sociedades pacíficas, justas e inclusivas que estén libres del temor y la violencia. No puede haber desarrollo sostenible sin paz, ni paz sin desarrollo sostenible". Sin embargo, no se ahonda empero en la paz como un fundamento básico para el desarrollo sostenible. "En definitiva, la paz se sitúa como una cuestión central en las intenciones de los Estados con la formulación de la Agenda 2030 pero, sin embargo, la noción de paz no ha merecido una atención específica y detallada (A/Res/70/1: 16).

La paz del Objetivo 16 admite diversas perspectivas de análisis: diversas perspectivas (moral, jurídica y política; dimensiones que tendría la paz en la actual sociedad internacional (Díaz Galán: 2018, p.249); proyección en los derechos humanos (derecho humano a la paz); dimensiones de la paz (positiva y negativa); su vinculación con otros ODS y tantas otras. Conviene examinar brevemente estas posibilidades.

La varias lecturas de la paz (moral, jurídica y política) no solo no son excluyentes sino que se complementan. Aquí no se trata de reivindicar que la defensa del derecho a la paz se considere como un derecho humano, lo cual no significa renunciar a defender el fundamento 
moral de un derecho a la paz. La articulación de la paz se fundamenta tanto en ese primer nivel moral como en un segundo nivel de plasmación jurídica. El pacifismo y las sociedades pacíficas se construyen a partir de evitar injusticias y de considerar la paz como un medio para la consecución de la justicia -y no como un fin en sí mismo- (Rodríguez Palop: 2006, p.52). La paz no sólo equivale a ausencia de conflictos bélicos sino que remite a una situación de orden -no cualquier orden- sino uno que esté sometido a determinados criterios y requisitos (Ferrajoli: 2004; Kelsen: 2017). Es decir, la alternativa al conflicto no ha de ser necesariamente la paz sino una dialéctica flexible y abierta. Por tanto, su fundamento moral debería ser la solidaridad, lo cual exige la apertura del círculo de "nosotros" con respecto a los "otros". Es decir, la superación de la dialéctica amigo/enemigo. Esta cultura de solidaridad también exige la sustitución de las estructuras de dominación por estructuras de cooperación. En el ámbito jurídico el derecho a la paz debería articularse como un principio rector, que oriente la educación (en y para los derechos humanos) y, principalmente, los derechos que derivan o guardan relación con la paz y las sociedades pacíficas. Basta pensar en las nuevas formas de esclavitud (servidumbre doméstica, explotación reproductiva, matrimonio forzado e infantil y trata de personas) y tantas otras modalidades de vulneración de derechos que acaban generando violencia y conflictos. Además de la dimensión moral y jurídica, la paz así entendida también requiere del orden político. Una democracia deliberativa, que haga posible espacio de diálogo y de argumentación como forma de gestionar los conflictos. Y en el orden internacional exigiría la adopción de medidas para consolidar una democracia cosmopolita y un fortalecimiento de la comunidad internacional superando la globalización que confunde. El proyecto de pacifismo cosmopolita kantiano ya preanunciaron esa línea hace siglos (Llano Alonso: 2002).

La potencialidad de las modernas tecnologías sumado a unas formas de comunicación a escala planetaria hace que se tome conciencia del daño que supondría un enfrentamiento bélico, del cual se tendría conocimiento en todo el planeta. Por ello, el tema de la paz ha adquirido un protagonismo en el sistema de las necesidades insatisfechas de los hombres y de los pueblos en estas últimas décadas (Pérez Luño: 2006, p.29). Ello explica la relevancia que ha adquirido el derecho a la paz, apoyándose en la solidaridad y en la cooperación -en cuanto derecho que se encuadra en la categoría de "derecho de tercera generación"-. De un anterior nivel de abstracción se ha evolucionado a un derecho que se realizan "con" los demás y "en" un contexto social e histórico determinado (Pérez Luño: 2006, p.36; Ara Pinilla: 1990, p.122 Ss).

A partir de la clásica distinción entre paz negativa — ausencia de violencia, represión e intimidación - y paz positiva - la ausencia de "violencia estructural" y la existencia de 
estructuras, políticas e instituciones que permitan la satisfacción de las necesidades humanas y el desarrollo de sus derechos y potencial- (Galtung 1964 y 1969) podría considerarse que el conjunto de la Agenda 2030, en tanto Agenda integral de desarrollo, universal y transformadora, es una Agenda orientada a la paz positiva. Desarrollo, seguridad y derechos humanos se inscriben en ese concepto de paz positiva que permite crear unas condiciones que hagan posible una visión más amplia que se extiende al desarrollo económico y social y a la gobernanza democrática. Baste citar el enfoque del Premio Nobel de Economía, Amartya K. Sen y su concepción del desarrollo como libertad, o del concepto de "seguridad humana" planteado en 1994 por Naciones Unidas, a la que define como ausencia tanto del miedo como de la necesidad.

La noción de paz, a su vez, se vincula con otros principios y metas tales como la justicia, la igualdad, la erradicación de la pobreza y el aprovechamiento de recursos naturales, que han sido recogidos en los ODS. Como señala M. Mesa, "la paz sólo puede ser genuina si se la carga de significado y se construye a través de la lucha contra la impunidad, la injusticia, la militarización, la discriminación, la violencia de género, la pobreza, la defensa de los derechos humanos y la sostenibilidad ecológica" (Mesa: 2017, p.18). La meta de construir "sociedades pacíficas, justas e inclusivas que proporcionen igualdad de acceso a la justicia” lleva a entender que la paz se configura como un objetivo transversal para poder llegar a la consecución de otros muchos.

(35) El desarrollo sostenible no puede hacerse realidad sin que haya paz y seguridad, y la paz y la seguridad corren peligro sin el desarrollo sostenible. La nueva Agenda reconoce la necesidad de construir sociedades pacíficas, justas e inclusivas que proporcionen igualdad de acceso a la justicia y se basen en el respeto de los derechos humanos (incluido el derecho al desarrollo), en un estado de derecho efectivo y una buena gobernanza a todos los niveles, y en instituciones transparentes y eficaces que rindan cuentas (A/Res/70/1: 11). (La cursiva es nuestra)

Se hace también referencia a que deben realizarse esfuerzos para resolver o prevenir los conflictos y consolidar la paz (destacando el papel de las mujeres en tal propósito) pero sólo se contemplan como deberos (morales), sin explicar cómo conseguirlo -desde una perspectiva jurídica, que hubiera sido lo adecuado-:

Debemos redoblar nuestros esfuerzos para resolver o prevenir los conflictos y apoyar a los países que salen de un conflicto, incluso velando por que las mujeres desempeñen su papel en la consolidación de la paz y la construcción del Estado. (La cursiva es nuestra).

Las causas de la violencia están casi siempre asociadas a la privación, la desigualdad, la injusticia, los agravios entre grupos sociales y la falta de acceso a los servicios básicos, entre otros factores. Por ello, la prevención de conflictos y la construcción de la paz puede ser una 
importante contribución al desarrollo sostenible y a la inversa. Romper los ciclos por los que la exclusión y la violencia se retroalimentan negativamente, a favor de sinergias positivas entre paz y desarrollo, requiere tanto de sistemas de alerta temprana, como de mayores capacidades nacionales y locales -lo que se ha llamado la "infraestructura de la paz"- para encauzar las tensiones por medios institucionalizados y pacíficos. Y para ello también es necesario promover la cohesión social y la participación inclusiva en la sociedad.

Yendo más allá de lo que se indica en las metas 1 y 2 del Objetivo 16 en relación a "reducir significativamente todas las formas de violencia (...) y "poner fin al maltrato, la explotación, la trata y todas las formas de violencia y tortura contra los niños" que supone también un alegato contra la violencia y un afirmación de la paz, lo cierto es que como principales retos que se identifican en el Objetivo 16 y que cuya erradicación contribuiría a la consolidación de la paz habría que señalar: la lucha contra el terrorismo y la delincuencia organizada. En definitiva, el Objetivo 16 menciona diversos aspectos relacionados con la paz y la seguridad internacionales pero no ofrece, como podemos observar, una noción de qué se entiende por paz internacional y tampoco indica cuáles son las metas que los Estados persiguen en este sentido (Díaz Galán: 2018, p.259).

La ONU ha elaborado Informes anuales de balance de la consecución (o no) de los ODS, publicados respectivamente en 2017, 2018 y en 2019, en los que describe el grado de implementación del ODS 16. Por su parte, la UNESCO también impulsa la cultura de la paz mediante el Programa para una Cultura de Paz y no Violencia, ${ }^{9}$ que incluyen, entre otras cosas, iniciativas a favor de la democracia y la ciudadanía mundial, el diálogo intercultural, la educación para la paz y los derechos humanos, y la construcción de la paz.

\subsection{De la cultura de la paz a la cultura de la mediación. Sus bases filosóficas}

La palabra paz deriva del latín pax (pacis) que significa “acuerdo o pacto". Originalmente la paz ha sido concebida como sólo la ausencia de guerras, ya que este concepto estaba centrado en los conflictos bélicos entre Estados Sin embargo, tal concepto de paz ha ido evolucionando, pasando de guerras entre países a enfrentamientos o conflictos en grupos sociales menores hasta llegar a los conflictos interindividuales. A todos estos niveles se refieren los ODS.

\footnotetext{
${ }^{9}$ Se considera que el conocimiento de los derechos y las libertades es una herramienta fundamental que garantiza el respeto de los derechos de todos. El Programa Mundial para la educación en Derechos Humanos guía el trabajo de la UNESCO en esta materia. https://es.unesco.org/themes/programas-construir-paz.
} 
Aunque aparentemente en las sociedades del siglo XXI hemos alcanzado unas cotas de paz altas, ello no significa que la violencia no persista aunque a veces sea de forma solapada (Garrido Gómez: 2011, p.31). A lo largo de la historia, han sido varios los iusfilósofos que han prestado especial atención a la paz tales como Hobbes (centrándose en la racionalidad filosófico-moral), Kant (centrándose en la racionalidad moral), Kelsen (centrándose en la racionalidad jurídica, es decir, en los tratados internacionales y en el Derecho internacional) o Ferrajoli (quien subraya que entre Derecho y guerra hay una contradicción, siendo el Derecho la negación de la guerra y la guerra la negación del Derecho).

En el siglo XXI la cultura de la paz se ha difundido ampliamente. Puede definirse como un conjunto de valores, actitudes y comportamientos, que rechazan la violencia y previenen los conflictos, tratando de solucionar los problemas mediante el diálogo y la negociación entre las personas y las naciones. Los derechos humanos colaboran activamente en la consecución de esa cultura de la paz.

Son varios los pasos que progresivamente se han ido dando para avanzar en la construcción de la paz -en los que no podemos extendernos ahora- (la resolución 53/243 “Declaración y Programa de Acción sobre una Cultura de Paz" de Naciones Unidas en 1999; el Manifiesto 2000 para una cultura de paz y no violencia; los Estudios de paz, la filosofía de paz, la resolución de conflictos, gestión y transformación de conflictos; el Fórum Barcelona 2004 sobre la paz; Ley 27/2005, de 30 de noviembre, de fomento de la educación y la cultura de la paz, en la que se encomienda al Gobierno español, desde la óptica de la paz, la incorporación de los valores de no violencia, tolerancia, democracia, solidaridad y justicia en los contenidos curriculares).

La construcción de la bases filosóficas de la paz suelen llevar a contraponerla a otros conceptos (paz / violencia) o bien a asimilarla a efectos beneficiosos (paz / seguridad) e incluso polos opuestos dentro del propio concepto (paz / paz positiva).

En cuanto a la primera, paz /violencia, como ha señalado el sociólogo y matemático noruego Galtung -pionero en los estudios sobre la paz-, el triángulo de la violencia permite comprender las distintas vertientes en las que es necesaria la paz. Aparte de la violencia directa, física o verbal y visible para todos, existen también la violencia estructural y la violencia cultural, fuerzas y estructuras invisibles, pero no menos violentas. Ellas son las raíces de la violencia directa y comprenden ciertas formas sociopolíticas y culturales de una sociedad: las estructuras violentas como represión, explotación, marginación; y la cultura de la violencia como la legitimación de la violencia en el racismo o sexismo. (Galtung: 1998). La paz no consiste solo en la ausencia de enfrentamiento bélico sino que hay otras muchas acciones y 
conductas que provocan esos conflictos y que incrementan el grado de violencia, tales como el racismo, la xenofobia y la intolerancia. La finalidad que se proponen las acciones pacíficas no es sólo la ausencia de conflictos sino también evitarlos. Robos, homicidios, secuestros, tráfico de armas y tantas otras acciones que se inscriben en el ámbito del delito penal inciden en la paz, causando grave daño a una sociedad pacífica.

En cuanto a la segunda, paz /seguridad, en sociedades democráticas y pacíficas la seguridad (jurídica) se convierte en uno de los principales fines a garantizar (Ferrari, 1989) para hacer posible el ejercicio de las demás libertades y derechos. Desde los orígenes del contractualismo, el tránsito del estado de naturaleza al estado de sociedad supone su conversión en un Estado de seguridad. De esa seguridad jurídica se puede transitar hacia una seguridad ambulatoria o la adopción de medidas que hagan posible esa seguridad y que se plasman en que, por ejemplo, caminar por las calles sea muy diferente en una ciudad europea a una ciudad latinoamericana. De ahí que la lucha contra la violencia y la búsqueda de la seguridad se perfilen como dos ejes para entender la cultura de la paz actual que permite comprender que para lograr un desarrollo sostenible sea necesario crear las condiciones de una sociedad pacífica.

Galtung completa su explicación sobre la paz con el tercer binomio de paz negativa (no guerra) / Paz positiva (no violencia). La paz negativa se refiere a la ausencia de violencia personal, guerras, terrorismo y disturbios mientras que la paz positiva se da cuando existe una ausencia de violencia estructural, es decir, ausencia de pobreza, hambre, discriminación y contaminación. Subraya que la contraposición de la paz no es la guerra, sino la violencia. Cuando termina un enfrentamiento es precisamente cuando hay que empezar a trabajar por la paz para que dure más allá de lo que supone el fin de un enfrentamiento. Ello permite diferenciar tres etapas acumulativas a lo largo de las cuales se ha desarrollado este binomio: Primera etapa: Paz negativa y estudios científicos para la guerra; Segunda etapa: Paz positiva, estudios sobre cooperación al desarrollo, desarme y refugiados; Tercera etapa: Paz cultural y Cultura de paz, nuevas culturas versus nuevas realidades.

Todo ello desemboca en la necesidad de dar a conocer una cultura de la paz, apoyada en una filosofía de la paz. Es prioritario un gobierno que fomente la tolerancia, la alteridad, para formar una ciudadanía que esté educada en competencias de diálogo, empatía, cooperación y construcción de acuerdos tanto a nivel individual como social y entre naciones. Junto al arreglo pacífico de los conflictos, se requieren contextos de democracia en que se respeten los derechos humanos; instituciones democráticas; la transparencia y la rendición de cuentas en la gestión de los asuntos públicos; la educación es una pieza fundamental para lograr esa cultura de la paz. Por su parte, la cultura de mediación se inscribe como un instrumento relevante dentro de la 
cultura de la paz. La educación para la paz tiene dentro de sus ejes clave la resolución pacífica de conflictos y la justicia requiere de algo más que vencedores y vencidos. Es una justicia también para la paz. (Pérez Sauceda: 2015, p.129).

Ello nos lleva a reflexionar sobre los fundamentos filosóficos de la mediación. Una de las claves de su defensa -y éxito- es que permite construir una solución adecuada a cada caso. La mediación de conflictos es una forma de autocomposición que contribuye a que las partes en conflicto puedan alcanzar soluciones más adaptadas a sus necesidades e intereses que las que podrían obtener por la mera aplicación de la previsión legal. En realidad, esta idea que subyace a la mediación no es nueva. Baste recordar el concepto de equidad que configuró Aristóteles cuya esencia era dar también la solución más adecuada a un conflicto, atendiendo a la situación concreta. Si se repasan los apenas tres párrafos en que convencionalmente se divide el célebre pasaje sobre la equidad de la Ética nicomáquea (el Cap.10 del Libro V), nos dice, en primer lugar, que la equidad se inserta en la justicia pero que sin embargo, es mejor que la justicia (1137b10); en segundo lugar, advierte que el legislador incurre en un error, un déficit o una insuficiencia. De aquí inicia la necesidad de la corrección en que consiste la equidad, cuando no es posible hablar en sentido universal rectamente (1137b13-17). El "error" no se imputa a la ley ni al legislador, sino a la "naturaleza de la práctica" [1137b19-20]); en el tercer párrafo, Aristóteles no se refiere ya al legislador sino al juez a quien incumbe corregir ese error, quien debe aplicar un juicio de equidad en el caso particular capaz de subsanar la insuficiencia en que ha incurrido el legislador: "Por tanto, cuando la ley se expresa universalmente y surge a propósito de esa cuestión algo que queda fuera de la formulación universal, entonces está bien, allí donde no alcanza el legislador y yerra al simplificar, corregir la omisión” (1137b20-23). Y nos dice además cómo debe de hacerlo: el método que el juez debe seguir para corregir ese error: que consiste en recurrir a "aquello que el legislador mismo habría establecido en su ley si hubiera conocido el caso" (1137b23-24). La naturaleza de la equidad es precisamente esta: una corrección de la ley cuando ésta es deficiente debido a su universalidad" (1137b26-27) (Vega: 2014, pp.113-119).

En la mediación subyace un principio de justicia como es el de contribuir a que las partes alcancen soluciones más adecuadas a sus intereses y necesidades. Ahora bien, esta fundamentación de la mediación conlleva una consecuencia como la de configurar los tribunales de justicia como último recurso a la hora de resolver un conflicto. Y ello con la consecuencia de deslegalizar la ley en beneficio del principio dispositivo. Este planteamiento podría derivar en unos interrogantes de los que, al menos, hay que plantear: esas soluciones más adecuadas a los intereses de las partes, ¿son justicia? Y desde la tutela judicial, ¿cómo 
inciden en el derecho a la asistencia letrada y el derecho a la acción en un proceso?. Baste afirmar ahora que se ha justificado que las formas de gestión positiva de los conflictos no sólo no atentan contra el derecho de acceso a la justicia sino que ayudan a su consolidación.

Contrasta la constante presencia que tiene el conflicto con la escasa atención que le han dedicado tanto teóricos (juristas) como abogados (prácticos) del Derecho, que "se han desentendido de la problemática del conflicto". La causa principal de esa desatención se encuentra en la aceptación de la denominada "norma de clausura", enunciada por la Teoría Pura del Derecho. "La consecuencia principal del principio de clausura es la idea de que el ordenamiento jurídico es un sistema cerrado de normas que resuelve todos los enfrentamientos posibles”. El Derecho es, en esencia, un método institucionalizado_de solución de conflictos. Método institucionalizado que, además, no es pacífico, sino esencialmente violento: El sistema jurídico es un método violento y no pacífico de resolución de controversias porque recurre al uso o a la amenaza de la fuerza en forma de sanción (impuestas por jueces o sus ejecutores como consecuencia de una conducta antijurídica) y porque implica la privación de algo valioso y que son aplicados con independencia o contra la voluntad del sancionado". A todo ello hay que sumar la imposibilidad de la metodología jurídica para solucionar todos los conflictos. Por tanto, hay que presentar otras alternativas. La formulación de una teoría general del conflicto vinculada al mundo jurídico conlleva, necesariamente, un nuevo rol para juristas y abogados. Desde la perspectiva iusfilosófica, su formulación se ajusta mejor a los nuevos enfoques surgidos de la crisis del positivismo. Como afirma Pérez Luño: «frente a las alternativas aislacionistas y autorreferentes (autopoiéticas) del Derecho, parece oportuno avanzar hacia marcos teóricos omnicomprensivos».

\subsection{Las posibilidades de implementación de las sociedades pacíficas (ODS 16) a través de la mediación}

Junto a los sistemas judiciales estatales, se convive con unos medios complementarios que permiten, en unos casos obviar los procesos judiciales y en otros, minimizarlos, pudiendo hablar en sentido positivo de una idea de "justicia compartida". Y es desde ella -como acertadamente señala Barona Vilar- donde se incorpora progresivamente ese nuevo paradigma de justicia que ofrece un nuevo concepto de Access to Justice, en el que se ofrece lo que se ha denominado “The multi-rooms Justice System”, un modelo en el que las ADR y la Jurisdicción coexisten como mecanismos complementarios de tutela de los ciudadanos. La mediación, como metodología y proceso colaborativo para la gestión positiva de conflictos es una herramienta fundamental en el desarrollo de la cultura de paz. Asimismo, los profesionales de la mediación, 
como actores relevantes para generar un diálogo pacífico entre las personas mediadas y construir espacios facilitadores de acuerdos, encuentran un marco idóneo para promover actuaciones de un alto impacto en la consecución de la mayoría de los Objetivos mencionados. La mediación puede definirse como un modelo de solución de conflictos que, mediante la intervención de un "tercero" neutral e imparcial, ayuda a dos o más personas a comprender el origen de sus diferencias, a conocer las causas y consecuencias de lo ocurrido, a confrontar sus visiones y a encontrar soluciones para resolver aquéllas. Si bien la mediación extrajudicial (privada) no ha conseguido que su implantación sea más que excepcional, distinta es la mediación intrajudicial que, mediante proyectos y programas pilotos en numerosos tribunales españoles ha ido posibilitando la difusión y práctica de la mediación.

Es en la consecución del Objetivo 16 de "construcción de la paz", donde la mediación puede desplegar toda su capacidad para transformar y mejorar la vida de las personas. Concretamente el ODS 16 presenta unas metas como son la consecución de la paz, resolver o prevenir los conflictos e igualdad de acceso a la justicia que pueden llegar a alcanzarse de forma idónea con la mediación. En general, los mecanismos alternativos de solución de conflictos (MASCs) comparten estas mismas metas que se propone el ODS 16. "Existen muchos conflictos que no llegan a los tribunales y se resuelven por otras vías. Así, por ejemplo, todas las que se pueden encontrar dentro de los denominados métodos alternativos de solución de conflictos (MASC), resolución alternativa de litigios (RAL) o métodos alternativos de resolución de conflictos (MARC o ADR, por su acrónimo en inglés), que incluyen vías alternativas como la mediación, la negociación, la conciliación, el derecho colaborativo y el arbitraje". ${ }^{10}$

Partiendo de su propia fundamentación teórica, la mediación tiene diferentes funciones a través de las que puede colaborar en la consecución del mencionado Objetivo 16 y en la consiguiente transformación social. De ellos, destacamos tres:

- Función de prevención de conflictos y construcción de una dinámica relacional no confrontativa.

- Función de gestión positiva de conflictos y de resolución de conflictos mediante el diálogo, la comunicación, la búsqueda de intereses comunes y la consecución de acuerdos satisfactorios para todas las partes implicadas.

- Función educativa para las personas, organizaciones y la sociedad en general, en la cultura de respeto por los diferentes puntos de vista, comunicación no violenta, colaboración y construcción de la paz.

10 Ley 24/2018, de 5 de diciembre, de mediación de la Comunitat Valenciana. https://www.boe.es/diario_boe/txt.php?id=BOE-A-2019-966 
Junto a la paz, la prevención y resolución de conflictos, y la igualdad en el acceso a la justicia, se erigen en tres claves del ODS 16, y que pueden lograrse a través de la mediación, como uno de los principales instrumentos dentro de los que sería un sistema de "justicia integral" (Barona Vilar:: 2016, p.16 ss). Es decir, junto a la mediación -intrajudicial y extrajudicial-, el Derecho colaborativo (Soleto Muñoz) y otras fórmulas, siempre que contribuyan a facilitar el diálogo entre las partes enfrentadas, y que permitan acercar posiciones e intereses, se estará contribuyendo a un desarrollo sostenible porque se está impulsando una sociedad pacífica, inclusiva, que permite el acceso a la justicia de todos, y que intenta prevenir los conflictos o, en su caso, resolverlos.

El derecho constitucional de acceso a la justicia, en un sistema en el que la globalización, la crisis del positivismo jurídico, la presencia de una sociedad y de un Estado en red, han provocado profundas mutaciones en el propio concepto del Derecho, permite sostener que un sistema de "justicia integral", flexible, capaz de adaptarse y de gestionar realmente el conflicto de que se trate, se configura como el sistema actualmente idóneo para hacer posible el acceso a la justicia. Los antiguos moldes jurídicos no sirven.

Por tanto, para concretar la implantación del ODS 16 se propone:

- Que las Administraciones desarrollen la idea de los juzgados o Tribunales "multipuertas"; los ciudadanos deben encontrar información sobre la medición en las sedes de los tribunales (multidoor court-house).

- Integración del concepto de "Justicia integral" en la consecución de la sostenibilidad. La paz es un pilar central para el logro de la Agenda 2030.

- Consolidación de políticas públicas que garanticen el acceso de los ciudadanos a la justicia y ello tanto a través de la mediación como de otros mecanismos de gestión de conflictos. Ello exige retomar el Anteproyecto de Ley de Impulso a la Mediación, aprobado por el Consejo de Ministros de 11 de enero de 2019. El texto fue propuesto en la XII Legislatura que finalizó, de manera sobrevenida, el 5 de marzo de 2019 y que debe ser urgentemente retomado por el Gobierno actual. En este Anteproyecto se contemplan tres artículos para realizar reformas en diversas leyes con el fin de para fomentar la mediación. Precisamente, en uno de estos preceptos se incluye la mediación como una prestación más a incluir en la Ley 1/1996, de 10 de enero, de asistencia jurídica gratuita que permitiría integrar a la mediación como un medio más de acceso a la justicia. Es decir, la mediación pasa a ser un servicio más ofrecido por la Administración de Justicia y si el justiciable carece de medios económicos tendrá derecho a que el Estado les facilite gratuitamente dicho servicio (como ya existe en la Comunidad Valenciana). ${ }^{11}$ Con todo, "la gratuidad de la mediación garantizada por la Ley sólo afecta a aquellos supuestos en los que se ha establecido como obligatoria o requisito de procedibilidad" cuando "lo deseable sería no limitar este beneficio de asistencia jurídica gratuita en la mediación "tipificada como obligatoria" y que se extendiera a cualquier controversia que se plantee, cuando el ciudadano tenga reconocido el citado derecho" (García Villaluenga y Vázquez de Castro: 2020, p. 26).

\footnotetext{
${ }^{11}$ Obsérvese que el derecho de acceso a la justicia tiene una escasa, por no decir nula, relación con la noción de paz. Una vez más, el ODS 16 se presenta como una amalgama de transformaciones cuya conexión resulta un tanto forzada. Sin embargo, la Resolución 70/1 ha decidido incorporar las dos cuestiones dentro del mismo Objetivo.
} 
- Aprovechar las oportunidades que ofrecen las necesidades surgidas como efecto del Covid-19 para realizar reformas estructurales. En relación a la propuesta de promoción e impulso de la mediación, debe subrayarse que como consecuencia del incremento de acciones judiciales que llegarán en los próximos días a los tribunales como efecto del Covid-19 en tantos ámbitos de la vida de las personas, una vez concluido el confinamiento y la suspensión de plazos administrativos y judiciales, el Ministerio de Justicia español está ultimando un Anteproyecto de Ley de medidas procesales, tecnológicas y de implantación de medios de solución de diferencias. Entre los diversos objetivos que se plantea el Anteproyecto está el de promover un sistema extrajudicial de resolución de controversias paralelo y complementario a los juicios para evitar la "hiperjudicialización de la vida en sociedad" y descargar a los tribunales de la carga de trabajo que van a recibir. Las ventajas que recurrentemente se suelen citar para defender el sistema extrajudicial de conflictos de rapidez, agilidad y economía para las partes, cobran ahora un especial significado cuando tantas sociedades, empresas, negocios, familias y otros muchos afectados, necesitan imperiosamente una solución urgente a sus conflictos para poder continuar con su actividad económica, desarrollando su trabajo o solventados sus problemas familiares. Constituye una excelente oportunidad para llevar a cabo una implantación seria de estos mecanismos. Concretamente, el Ministerio de Justicia propone regular un sistema que fomente el uso de la negociación entre las partes antes de interponer una demanda en el orden civil; y que una vez iniciada la vía judicial el juez o el tribunal puedan derivar a las partes a la mediación para intentar buscar un acuerdo negociado.

- Diseño e implementación de un Plan integral / Nacional de Cultura de la paz, empezando por las instituciones -como las Universidades-. ${ }^{12}$

- Impulso de una educación en y para los Derechos humanos que esté fuertemente vinculada a la consecución de los ODS. Es más, cada ODS no deja de ser una proyección de uno o varios derechos humanos. La educación tanto en derechos humanos como en los propios ODS contribuirá al desarrollo sostenible de nuestras sociedades. La Agenda 2030 no puede quedar desligada de los derechos humanos. - Colaboración entre el sistema de tutela judicial y los operadores jurídicos, así como la doctrina y los propios docentes y Facultades de Derecho para lograr que los mecanismos alternativos / complementarios de resolución de conflictos encuentren el lugar que les corresponde -y que los ciudadanos necesitan- en un sistema judicial del siglo XXI.

Consejo General del poder Judicial (CGPJ), Consejo General de la Abogacía Española (GAE), Grupo Europeo de Magistrados por la Mediación (GEMME) España y Europa, Conferencia de Universidades para la Mediación y el Conflicto (CUEMYC) y otras Asociaciones que trabajan para impulsar la mediación y garantizar la calidad, tanto en los Cursos de formación de mediadores como en el ejercicio profesional de la mediación, están llamadas a reforzar sus alianzas - en formato "Alianzas SMART"- en aras de una integración de las diversas formas de gestionar positivamente los conflictos como elemento imprescindible que facilitará el desarrollo sostenible tanto a corto plazo, para los próximos meses, como a largo plazo.

\footnotetext{
${ }^{12}$ El Profesor de la UANL (México), Dr. D. Francisco Gorjón Gómez, reputado jurista y mediador, ha presentado un Plan de este tenor ante las autoridades mexicanas, en febrero de 2020.
} 


\section{GOBIERNOS COMO RESPONSABLES DE LA IMPLEMENTACIÓN DEL ODS 16}

Las diversas instituciones y Gobiernos - a nivel internacional, ${ }^{13}$ regional europeo, nacional, autonómico y local- han sido designadas como responsables de la implementación y seguimiento de tal implantación, de la Agenda 2030. Transcurridos cuatro años de la aprobación de la Agenda, conviene detenerse brevemente en revisar cómo se está llevando a cabo la consecución del ODS16, haciendo especial referencia a la consecución de la paz y de sociedades pacíficas.

\subsection{La implementación del ODS 16 en el ámbito de la Unión Europea}

En relación al ámbito europeo, ${ }^{14}$ se ha trabajado con diversos instrumentos con la finalidad de definir un marco de seguimiento y de indicadores para informar adecuadamente sobre la materia y que fundamentara los procesos de toma de decisiones de la Unión. Excedería los límites propuestos en este estudio la realización de un análisis de los pasos y medidas adoptadas por parte de las instituciones de la UE para la implementación de los ODS. Por ello, vamos a limitarnos a subrayar algunas de las ideas principales con respecto al nivel general de satisfacción de implementación de los ODS en la UE para, después, centrarnos en el ODS 16, que constituye el objeto principal de este trabajo.

En este sentido, se pueden enumerar diversos órganos e instrumentos que están aunando esfuerzos para la progresiva implementación de los ODS para el año 20230, tales como

\footnotetext{
${ }^{13}$ El Secretario General, en cooperación con el sistema de las Naciones Unidas, ha ido presentando, anualmente, el informe sobre los progresos realizados en la consecución de los Objetivos de Desarrollo Sostenible. Vid: Informe del Secretario General (E/2018/66, 21 Mayo 2018). http://undocs.org/es/E/2018/66; Informe de los Objetivos de Desarrollo Sostenible 2018. http://links.uv.es/wek3Jz7; también, vid. la base de datos en línea de acción de los ODS del sistema de las Naciones Unidas es el repositorio de acciones, iniciativas y planes de la familia de las Naciones Unidas sobre la aplicación de la Agenda 2030 y los Objetivos de Desarrollo Sostenible (ODS). Base de datos en línea de los ODS de Naciones Unidas.

https://sustainabledevelopment.un.org/content/unsurvey/index.html

También, vid. tabla se presentan los cuatro elementos característicos de la inteligencia artificial para el desarrollo en relación con los ODS. CEPAL (2018). Datos, algoritmos y políticas: la redefinición del mundo digital. Santiago, UN-CEPAL, p.179. https://repositorio.cepal.org > bitstream > handle > S1800053_e

${ }^{14}$ Agenda 2030. Ministerio de Asuntos Exteriores, Unión Europea y Cooperación http://www.exteriores.gob.es/Portal/es/PoliticaExteriorCooperacion/Agenda2030/Documents/Informe\%20de\%2 0Progreso\%202019.pdf

Progress towards the Sustainable Development Goals (2018-2019)

https://sustainabledevelopment.un.org/content/documents/22700E_2019_XXXX_Report_of_the_SG_on_the_pr ogress_towards_the_SDGs_Special_Edition.pdf

Reshaping governance for sustainability (2016-2019)

https://www.2030spotlight.org/en/book/1883/chapter/reshaping-governance-sustainability
} 
Documentos de trabajo, ${ }^{15}$ publicación de Informes ${ }^{16}$ y el impulso dado por el Observatorio Europeo de los ODS. ${ }^{17}$ En relación al Informe Sustainable development in the European Union, de 2017, el Observatorio ha presentado cinco conclusiones relevantes entre las que destacamos:

- El Informe no aborda todas las dimensiones del desarrollo sostenible y se centra en medir las soluciones existentes en lugar de analizar lo que se necesita para hacer realidad la Agenda 2030;

- Las principales tendencias sociales, medioambientales, económicas y tecnológicas reflejadas en el Informe están subordinadas a las prioridades actuales de la Comisión a través de la elección de determinados indicadores. Por ello, el Informe presenta una imagen sesgada del rendimiento de la UE. Por ejemplo: el ODS 12 sobre consumo y producción sostenible recibe una alta puntuación en el progreso, mientras que las evaluaciones de la Red de Soluciones de Desarrollo Sostenible $(\mathrm{SDSN})^{18}$ y la Agencia Europea del Medio Ambiente $(\mathrm{EEA})^{19}$ muestran claramente que los países de altos ingresos fracasan en este objetivo;

- La metodología usada no permite mostrar la distancia existente y a qué velocidad debemos avanzar para que la UE alcance los ODS antes de 2030;

- El informe no mide el impacto de la UE en el desarrollo sostenible a nivel mundial: no ilustra si los esfuerzos europeos en cooperación para el desarrollo son suficientes para contribuir a la reducción de pobreza y desigualdad (Aidwatch, una evaluación de la Ayuda Europea) ${ }^{20}$, ni si la UE reduce su impacto negativo en el resto del mundo debido al consumo excesivo, el agotamiento de los recursos, su huella ecológica, así como la negligencia con los derechos humanos y la explotación de la mano de obra barata, todos ellos enormes desafíos en la implementación de los ODS de la UE;

- El Informe omite datos críticos para abordar el principio de la Agenda 2030 de "no dejar a nadie atrás" y es débil a la hora de medir cómo se reducen las desigualdades dentro de la UE.

A partir de esas conclusiones, el Observatorio realizó algunas reflexiones y propuso la adopción de ciertas medidas, ${ }^{21}$ a las que seguidamente se hará referencia:

\footnotetext{
${ }^{15} \mathrm{El}$ documento de "Conclusiones del Consejo de la Unión Europea para una agenda transformativa post 2015" establece la oportunidad de encarar la nueva Agenda desde una perspectiva orientada hacia la persona y basada en los derechos humanos. El Documento de Reflexión para una Europa sostenible de aquí a 2030, de la Comisión Europea y publicado en enero de 2019 (COM (2019) 22 de 30 de enero de 2019) profundiza en algunas cuestiones.

${ }^{16}$ Entre esos Informes pueden destacarse: el Informe de Síntesis del SGNU. The Road to Dignity by 2030: Ending Poverty, Transforming All Lives and Protecting the Planet Synthesis Report of the Secretary-General. On the Post-2015 Agenda https://www.un.org > disabilities > documents > reports >; el primer Informe sobre el desarrollo sostenible en Europa, " Comunicación de la Comisión al Parlamento europeo, al Consejo, al Comité económico y social europeo y al Comité de las regiones, Estrasburgo, 22.11.2016 COM(2016) 739 final; el Informe Sustainable Development in the European Union. Overview of progress towards the SDGs in an EU context Eurostat, publicado en 2017. <https://ec.europa.eu > KS-01-17-796-EN-N.pdf>; el Informe Sustainable Development in the European Union - 2018.Monitoring report on progress towards the SDGs in an EU context. $<$ https://www.ecologic.eu > ...>.;

${ }^{17}$ Futuro en común. https://futuroencomun.net/progreso-europeo-inadecuado-en-los-objetivos-desarrollosostenible-ods/16/; también: https://www.sdgwatcheurope.org/

${ }^{18}$ Red de Soluciones de Desarrollo Sostenible (SDSN) <https://www.sdgindex.org/> .

${ }^{19}$ Agencia Europea del Medio Ambiente (EEA) <https://www.eea.europa.eu/soer-2015/europe/consumption>.

${ }^{20}$ Coordinadora de Organizaciones de cooperación para el desarrollo <https://coordinadoraongd.org/2017/10/europa-cumplira-07-2052/>.

${ }^{21}$ Se trata de cuatro medidas: i) Revisar los indicadores con una contribución adecuada de la sociedad civil; ii)
} 
En cuanto al ODS 16 (Paz, justicia e instituciones fuertes) en la Unión Europea cabe subrayar que goza, en líneas generales, de un nivel satisfactorio, como avalan las estadísticas. Abarca áreas tales como paz y seguridad; acceso a la justicia y confianza en las instituciones, a las que se hará una breve referencia.

Así, en relación a la paz y la seguridad, la Unión Europea presenta un resultado de los más exitosos en cuanto a los proyectos de paz en el mundo. Tomando como guía el Tratado de Roma, firmado en 1957, la Unión puede recordar 60 años de paz y democracia y solidaridad. En 2012, la UE recibió el Premio Nobel de la paz por avanzar en las causas de la paz, reconciliación, democracia y derechos humanos en Europa. Actualmente, las políticas y la legislación de la UE se orientan por los principios contemplados en el Tratado de la Unión Europea y en la Carta de los Derechos Fundamentales de la UE -más ambiciosos que las metas establecidas en el ODS 16 - así como por el Tratado de Lisboa, que entró en vigor en 2009. Con "un área de justicia y derechos fundamentales basado en la confianza mutua", entre las prioridades de la UE está la lucha contra la corrupción, impulso de la igualdad de género y protección de la seguridad de las personas, entre otras. Las acciones criminales son uno de las causas más obvias de inseguridad. Las muertes por homicidios han disminuido constantemente en la UE desde 2002, alcanzando una tasa de 0,7 muertes por cada 100000 personas en 2014. Sin embargo, el homicidio sigue siendo aproximadamente el doble hombres como para mujeres. La seguridad personal también puede verse amenazada en la propia casa. Acabar con la violencia de género es uno de los grandes retos pendientes en los países de la UE.

En cuanto al acceso a la justicia, calidad, independencia y eficiencia son algunos de los parámetros esenciales de una 'Sistema de justicia efectivo". Además de suficientes recursos financieros, los jueces en los tribunales de justicia deben ser capaces de tomar decisiones sin interferencia o presión de la política u otros actores económicos, para asegurar que los individuos y las empresas pueden disfrutar plenamente de sus derechos. En 2017, más de la

\footnotetext{
Elaborar los sucesivos informes evitando la tentación de medir solo los méritos y apostar por una visión objetiva y comprehensiva de la realidad que incluya la participación de la sociedad civil; iii) Desarrollar un marco de seguimiento con foco en las políticas externas e internas; iv) El ejercicio de revisión de la implementación de la Agenda 2030 debe nutrir los procesos de decisión y una transformación real de las políticas europeas a favor de un avance del desarrollo sostenible en todas sus dimensiones (económica, social, ambiental y de gobernabilidad). En el ámbito de la Unión Europea, la implementación de los ODS trabaja con diversos escenarios de que debe destacarse el $n^{\circ} 6$, cuyo propósito es construir una Europa sostenible para los ciudadanos de la UE y que, a la vez, sea un conductor para la sostenibilidad tanto en Europa como allende de nuestras fronteras. Se augura que la coherencia de las políticas como objetivo clave tendrá como resultado el fin de las externalidades negativas de las políticas nacionales para el Sur Global. Asimismo, se plantea que las empresas y sus filiales fuera de la UE y en todas sus cadenas de suministro tienen la obligación legal de evaluar, mitigar y prevenir los impactos negativos sobre el medio ambiente y los derechos humanos de sus actividades comerciales a nivel mundial. (Sexto escenario para el futuro de la Unión Europea, una Europa sostenible para los ciudadan@s).
} 
mitad de los habitantes de la UE calificó la independencia de los tribunales y jueces en su país como buenos ("muy buenos" o 'Bastante bueno'). Crimen, violencia o el vandalismo en los barrios de la UE ha disminuido ligeramente o ha caído entre 2010 y 2015.Las personas que viven en en las ciudades son mucho más afectados por estos problemas que aquellos que viven en menos áreas pobladas. El presupuesto gastado en los tribunales de justicia de la UE tiene aumentó desde 2010, llegando a casi 50000 millones de euros en 2015.

En cuanto a la confianza en las instituciones, según el Tansparency International's Corruption Perceptions Index, los Estados miembros de la UE continuaron clasificándose entre los países menos corruptos del mundo en 2016. La corrupción percibida fue la más baja en países del norte de Europa. Las instituciones son importantes para las democracias efectivas. Ha aumentado la confianza de los ciudadanos la probabilidad de que voten en democracia elecciones. Sin embargo, en la última década la UE ha visto una considerable disminución de los niveles de confianza en sus principales instituciones. En 2016, solo el $42 \%$ de los europeos expresó confianza en el Parlamento Europeo, y los niveles de confianza para la Comisión Europea y El Banco Central Europeo estaba por debajo del $40 \%$.

\subsection{La implementación del ODS 16 en el ámbito nacional, autonómico y local}

A nivel nacional, en el marco del compromiso universal por la implementación de los ODS, en el marco de la cooperación española, se aprobó una Agenda post2015.22 En la citada Agenda se establecía que el ODS 16 podía concretarse en:

- Políticas necesarias para el fortalecimiento de la seguridad ciudadana, a través del fortalecimiento institucional de las fuerzas de seguridad de los estados: programas de formación para los cuerpos de policía, protección de personas, inmigración, fortalecimiento de las instituciones encargadas de la promoción y la defensa de los derechos humanos, formación de formadores en técnicas especiales para la prevención y lucha contra las amenazas para la seguridad y estabilidad y gestión de la inteligencia en la cooperación internacional. Cooperación y formación de los efectivos policiales y cuerpos de seguridad, responsables del orden y el control de las fronteras.

- Prevención de conflictos y mediación.

- Lucha contra la piratería y la delincuencia organizada.

- Cooperación en la lucha contra el terrorismo mediante la dotación de sistemas judiciales, penales y policiales respetuosos con los DDHH, con las prácticas de los estados de derecho y acordes con los convenios internacionales.

- Asistencia social, atención y asesoramiento a las víctimas de la violencia y el terrorismo.

- Fomento de la cultura de la paz como Bien Público Global.

\footnotetext{
${ }^{22}$ Vid. Consulta Nacional - Financiación del Desarrollo Post2015 - Salamanca, 25 de marzo de 2015; $2^{\text {a }}$ Consulta Nacional - Posición Española Agenda Post2015: Avances y Retos - Madrid, 15 de septiembre de 2014; y, Posición Española para la Agenda Post2015 (.pdf)

<https://www.cooperacionespanola.es/es/comunidad/cooperablog/ods-16-paz-justicia-e-instituciones-fuertes>.
} 
La paz y la seguridad se contemplan expresamente (Robles, 2015). En esa Agenda post2015 se definía la seguridad humana como "la condición de vivir libre de temor y de necesidad", siendo un concepto tan amplio que abarca "un abanico de amenazas, oscilando entre elementos tan dispares como los desastres medioambientales, las guerras, los conflictos comunitarios, la inseguridad alimentaria, la ausencia de democracia, la vulneración de los derechos humanos, las amenazas y los delitos contra la salud y la delincuencia, tanto organizada como común". En cualquier país, estas amenazas afectan a las personas y limitan las oportunidades de desarrollo humano. Se advertía que hay algunas dinámicas internas -como la debilidad institucional o la falta de gobernabilidad - que pueden llegar a convertirse en amenazas regionales o incluso globales. También las amenazas de carácter transnacional o global -el tráfico ilegal de armas, la violencia en cualquiera de sus formas, la trata de personas con fines de explotación sexual, laboral o de tráfico de órganos y de drogas- pueden incrementar las de inseguridad.

El objetivo es "el desarrollo de la paz, la justicia, la equidad y la seguridad en situaciones de conflicto y postconflicto, mediante la aplicación de acciones de prevención, el respeto a la legalidad internacional, la defensa de los DDHH, el apoyo a las víctimas y la recuperación del entorno físico, económico y social". La referencia que se hace a escenarios de conflicto o postconflicto hace que en el ámbito nacional español, a primera vista, pudiera pensarse que no es un objetivo primordial, ya que la situación es estable y pacífica. Sin embargo, a raíz de los recientes acontecimientos en Cataluña, con ocasión del movimiento independentista y de la protesta por la "sentencia del procés", el ODS 16, en cuanto a la paz, en situaciones de sociedades democráticas y pacíficas, no puede considerarse totalmente conseguido. ${ }^{23}$

Además de la Agenda post2015, en el ámbito nacional también se han aprobado Planes e Informes y se han designado responsables de tal implementación. En este sentido, en 2018 ha aprobado el "Plan para la implementación de la Agenda 2030" y se ha creado el Alto Comisionado para la Agenda 2030; ${ }^{24}$ en 2019 se ha aprobado el Informe sobre los mecanismos

\footnotetext{
${ }^{23}$ Un ejemplo de ello es que la Conferencia Universitaria para el Estudio de la Mediación y el Conflicto CUEMYC- consensuó un comunicado para hacer una llamamiento al cese de la violencia y a los cauces pacíficos de gestión positiva de los conflictos pero las Universidades catalanas no lo publicaron. <https://cuemyc.org/>.

${ }^{24}$ Plan de Acción para la implementación de la Agenda 2030.

http://www.exteriores.gob.es/Portal/es/PoliticaExteriorCooperacion/Agenda2030/Documents/Plan\%20de\%20Ac ci\%C3\%B3n\%20para\%201a\%20Implementacion\%20de\%201a\%20Agenda\%202030.pdf

En España se ha creado un Alto Comisionado para la Agenda 2030, al que se le ha encomendado "realizar el seguimiento de las actuaciones de los órganos competentes de la Administración General del Estado" para el cumplimiento de esas metas, "impulsar la elaboración y desarrollo de los planes y estrategias necesarios" para que España las alcance, y "evaluar, verificar y difundir el grado de avance en el cumplimiento de los objetivos". http://www.spainun.org/agenda-2030/
} 
e instrumentos de coordinación para la implementación de la Agenda 2030 en España (15 de febrero de 2019); en 2020 se ha creado el Ministerio de Derechos sociales y Agenda 2030 el cual, mediante el Real Decreto 206/2020, de 29 de enero, ha nombrado Director General de Políticas Palanca para el Cumplimiento de la Agenda 2030; también se están rastreando los indicios de implementación de cada uno de los ODS de la Agenda 2030. ${ }^{25}$ Asimismo, las empresas españolas también se han implicado en la consecución de estos ODS. ${ }^{26}$

A nivel de las Comunidades Autónomas los ODS se han insertado, a modo de metas a alcanzar, en las distintas políticas y acciones que se llevan a cabo -como en la Comunidad valenciana y la Comunidad de Castilla y León- ${ }^{27}$ También en el ámbito de los municipios ${ }^{28}$ como refleja la colaboración establecida entre el Ayuntamiento de Burgos y la Universidad de Burgos para el estudio y rastreo del grado de implantación de los Objetivos de Desarrollo Sostenible en la ciudad en estos cinco años, a la vez que se está trabajando en el diseño de una estrategia para la consecución de cada ODS-.$^{29}$

Por todo lo indicado, los principales responsables de la implementación de los ODS (y, por ende, del ODS 16) son los Gobiernos y las Administraciones. Se establece que el seguimiento y examen de la consecución de los Objetivos y las metas durante los quince años de implementación de la Agenda se realizará por nuestros Gobiernos que "son los principales responsables de realizar, en el ámbito internacional, nacional, regional y provincial, el

\footnotetext{
${ }^{25}$ Indicadores de la Agenda 2030. Instituto Nacional de Estadística (INE). https://www.ine.es/dynt3/ODS/es/index.htm

${ }^{26}$ Las empresas españolas ante la Agenda 2030.

http://www.exteriores.gob.es/Portal/es/SalaDePrensa/Multimedia/Publicaciones/Documents/4.\%20Las\%20empr esas\%20espa\%C3\%B1olas\%20ante\%20la\%20Agenda\%202030.pdf

${ }^{27}$ La Comunitat Valenciana y la implementación de los ODS a nivel local http://localizingthesdgs.org/library/202/3/La-Comunitat-Valenciana-y-la-implementacin-de-los-ODS-a-nivellocal-Una-Comunitat-comprometida-con-la-Cooperacin-y-la-Agenda-2030-para-el-Desarrollo-Sostenible.pdf Directrices de implementación de la Agenda 2030. Junta de Castilla y León. https://www.jcyl.es/web/jcyl/AdministracionPublica/es/Plantilla100/1284836243978/_/__

${ }^{28}$ Los Objetivos de Desarrollo Sostenible en 100 ciudades españolas (2018) http://reds-sdsn.es/wp-content/uploads/2018/10/Informe-urbano-REDS-ODS-2018-parte-I.pdf

${ }^{29}$ El Ayuntamiento de Burgos, en colaboración con la Universidad de Burgos, está desarrollando un proyecto de investigación sobre la implementación de los ODS en la ciudad de Burgos durante los años 2019 y 2020. http://www.aytoburgos.es/ods2030?title=\&field_ods_objeto_relacionado_ac_value_many_to_one=16\&field_ods _entidad_nid=All

Servicios Sociales (Ayto. Burgos)

http://www.aytoburgos.es/centros-civicos/la-red-de-centros-civicos/programacion-de-centros-civicos-octubre2019-enero-2020

También hay otras estadísticas e Índices correspondientes a otros Ayuntamientos.

Estadísticas de criminalidad por provincia. Ministerio del Interior

https://estadisticasdecriminalidad.ses.mir.es/

Índice de Transparencia de los Ayuntamientos

https://transparencia.org.es/indice-de-los-ayuntamientos-ita/
} 
seguimiento y examen de los progresos conseguidos. Pero junto a los gobiernos, también el sector privado y la sociedad civil deben contribuir a erradicar la pobreza, proteger el planeta y asegurar la prosperidad para todos como parte de una nueva Agenda de Desarrollo Sostenible.

\section{CONCLUSIONES}

PRIMERA. Hay una debilidad intrínseca en los ODS y es la falta de relevancia que se da de forma expresa a los derechos humanos en la Agenda 2030, sin que se haya establecido una específica y expresa correlación entre cada uno de los ODS y los respectivos derechos humanos con los que se vincula o en los que se podría plasmar. La única referencia expresa en los ODS a un derecho humano es precisamente el de la meta 16.3 cuando menciona el derecho a la justicia. Las escasas alusiones que se hace a los derechos humanos se encuentran en el Preámbulo de la Agenda 2030 y en alguna otra referencia a la Declaración Universal de Derechos Humanos y tratados internacionales de derechos humanos. Hay que presuponer que los derechos humanos permean todos los ODS pero en una Agenda programática de estas características debería haberse incidido y subrayado precisamente tal interrelación. De nuevo hay que recurrir a los sistemas internacionales de derechos humanos para que aporten a los ODS su carácter vinculante y sus mecanismos de garantías. Además, esta situación de debilidad se incrementa en la medida en que la Agenda 2030 no es un instrumento jurídicamente vinculante sino que se sitúa en el ámbito del soft law.

SEGUNDA. La Agenda 2030 se ha redactado pensando en problemáticas macro (guerras y conflictos bélicos entre países) y poco en los problemas micro (conflictos interindividuales o entre grupos). La Agenda 2030, pensada para "transformar nuestro mundo" -tal y como indica su propio título- se enfrenta a la dificultad de proyectarse en países y sociedades con sistemas jurídicos, sociedades, economías y políticas de diferente consolidación y complejidad. Algunas regiones gozan de niveles permanentes de paz, seguridad y prosperidad, mientras que otras caen en ciclos aparentemente eternos de conflicto y violencia. Los altos niveles de violencia armada e inseguridad tienen consecuencias destructivas para el desarrollo de un país, afectan el crecimiento económico y suelen derivar en agravios arraigados que pueden extenderse por generaciones. La violencia sexual, los delitos, la explotación y la tortura también son fenómenos generalizados donde existen conflictos o donde no hay Estado de derecho y los países deben tomar medidas para proteger a aquellos grupos que corren más riesgos y que son más vulnerables (mujeres, niños). Estas diferencias en el punto de partida en el que deben de aplicarse los ODS permiten entender que no pueden implantarse de modo 
uniforme en todos los países. Contextos de democracias débiles, situaciones de postconflicto, sociedades en las que impera la violencia, Estados con gobiernos corruptos, sociedades desiguales y marcadamente no inclusivas, constituyen un espectro que da lugar a diferencias notables en el punto de partida, lo que permite entender que el resultado al que se llegue en 2030 también será diferente. Baste comparar Iberoamérica con la Unión Europea (sociedades democráticas consolidadas, más igualitarias e inclusivas, con un sistema de justicia gratuita, en las que se lucha contra el fraude y el soborno, donde las instituciones públicas garantizan la transparencia y el acceso a la información por parte de los ciudadanos). Ahora bien, ello no significa que tanto en la Unión Europea como en España existan numerosas debilidades, desigualdades, casos de corrupción, formas de violencia y vulneraciones de derechos, situaciones todas ellas que marcan la senda de que debemos seguir "transformar nuestro mundo".

TERCERA. Los ODS han sido objeto de merecidas críticas en la medida en que se han formulado sin haber realizado un previo análisis sistemático sobre las causas subyacentes de los fenómenos que se pretenden resolver (o cuanto menos mitigar) así como por la confusión entre medios y fines. Sin embargo, la mayoría de instituciones y centros educativos (desde los niveles de primaria y secundaria hasta la Universidad) han realizado una lectura buenista del texto, tomando como referencia una conciencia social medioambiental y sobre otras variadas áreas (erradicación de la pobreza, lucha contra la desigualdad de género, etc.). Entre esas críticas se encuentran la de que los ODS mantienen una ideología excesivamente moderna y eurocéntrica que pretende legitimar su posición privilegiada mediante una concepción desarrollista de la sostenibilidad imposible de mantener desde un punto de vista sistémico. La presuposición a priori de que no existe contradicción alguna entre la sostenibilidad y el desarrollo se considera aceptada y aceptable en todos los ámbitos. Ahora bien, esto no significa que haya que seguir realizando una única lectura en clave de "la Europa colonial que nos sigue sometiendo". A nuestro juicio, desarrollo y civilización no son conceptos contradictorios. Es cierto que sostenible aplicado a desarrollo encierra una cierta paradoja. Pero precisamente la ética y el Derecho deben actuar para establecer los condicionantes, las limitaciones, los procedimientos que hagan posible ese crecimiento actual que impida a las generaciones futuras su propia existencia y desarrollo. La paradoja del desarrollismo consiste, pues, en que un rasgo que es ventajoso o incluso indispensable para la supervivencia a corto plazo de una sociedad, conduce a largo plazo a la desaparición de la misma. Pero sólo si ese desarrollismos se realiza de forma descontrolada. Articular las fórmulas para hacer posible ese desarrollo sostenible, esas 
"sostenibilidad sostenida" a nivel global es uno de los grandes retos que tienen ante sí los ODS.

CUARTA. EL ODS 16, de carácter marcadamente político, es considerado una "condición habilitante" del desarrollo sostenible, y no un "pilar" del mismo como los otros tres ya reconocidos -el social, el económico y el ambiental-.Tal y como se advertía ya en el Documento de Trabajo de cooperación sobre la Posición española Post2015, en el ODS 16 pueden diferenciarse dos objetivos separados. Por un lado asegurar el buen gobierno y las instituciones eficaces y, por otro, asegurar sociedades estables y pacíficas. Para cada uno establece una serie de metas basadas en la garantía de las libertades, la participación política, el acceso a los servicios públicos, reducción del soborno y corrupción para el primer objetivo. Y reducción de la inseguridad ciudadana y la violencia en cualquiera de sus formas, fortalecimiento de los cuerpos de seguridad y la garantía del acceso a la justicia para el segundo. A nuestro juicio, el enunciado del ODS 16 resulta excesivamente indefinido y amplio, a la vez que es uno de los que tienen una capacidad transformadora más amplia porque su éxito o fracaso incidirá en el propio éxito o fracaso de toda la Agenda. Resulta más clarificador desglosarlo en tres subobjetivos $-\mathrm{y}$ no en dos-. Ese triple objetivo incluye en primer lugar un área prioritaria sobre sociedades pacíficas e inclusivas; una segunda área sobre el imperio de la ley y el fortalecimiento de capacidades en las instituciones; y una tercera sobre el acceso a la justicia para todos.

QUINTA. Paz y desarrollo sostenible se requieren mutuamente. El logro del desarrollo sostenible, en todas sus formas y manifestaciones, requiere la adopción de medidas por parte de los Estados que fomenten la paz. En particular, se indica que el Objetivo 16 está orientado a promover "sociedades pacíficas". La paz se sitúa como una cuestión central en las intenciones de los Estados con la formulación de la Agenda 2030 pero, sin embargo, la noción de paz no ha merecido una atención específica y detallada. La consecución de una sociedad pacífica abarca desde la formación en una cultura de la paz, en edades tempranas -a través de la educación- como la implantación de sistemas de gestión positiva de conflictos -tanto para prevenir los conflictos como para gestionarlos cuando ya se han producido- como puede ser la mediación. En el ámbito español se están haciendo esfuerzos para impulsar la gestión complementaria de resolución de conflictos - como la mediación, la negociación colaborativa y otras fórmulas- en aras de lograr un sistema de "justicia integral". Sin embargo, hasta ahora no se han vinculado ni a la Agenda 2030 en general ni tampoco al ODS 16 en particular. Una de las razones de esta falta de interés tanto por fomentar una cultura de la paz - en la que el derecho 
a la paz, como derecho emergente, debería tener un papel esencial- como por la cultura de la mediación puede derivar de la falta de unas bases filosóficas sólidas y suficientemente difundidas. No se puede utilizar ni recurrir a procedimientos que siguen siendo desconocidos para buena parte de la ciudadanía. De ahí que la difusión de la cultura de la paz como de la cultura de la mediación a través de la educación sea una de las vías principales para la consecución del ODS 16.

SEXTA. La consecución de los 17 objetivos ODS compromete no solo a Gobiernos, Estados, organizaciones internacionales e instituciones públicas, sino también interpela a la sociedad civil y a todos sus actores. Por ello, el Gobierno y las Administraciones junto con la sociedad civil y empresas deben articular las políticas públicas impulsar planes y estrategias que promuevan el de implementación del ODS 16. Asimismo, deben implantar los instrumentos que resulten necesarios para articular la posibilidad de hacer un rastreo de los avances en la implantación de la Agenda 2030. El rastreo del seguimiento de la consecución de las metas en los diferentes niveles -supranacionales, nacionales, autonómicos y locales- no resulta fácil porque los indicadores de todos los ODS no tienen la misma uniformidad (hay indicadores de algunos ODS muy trabajados estadísticamente y completos y otros -como es el caso del ODS 16- en los que hay menos mediciones), por lo que realizar un rastreo de la consecución de las metas y submetas del ODS tropieza con dificultades. La clandestinidad que caracteriza ciertos delitos (trata de personas, sobornos, corrupción) dificulta su control. A ello hay que añadir la indefinición y amplitud del ODS 16, lo que nos lleva a pensar que será difícil tanto conseguir notables progresos en relación a este ODS en un plazo tan corto de tiempo como es el de diez años hasta llegar al 2030.

SÉPTIMA. Hay numerosos riesgos que podrían poner en peligro la paz y la seguridad internacionales y que no provienen necesariamente de las tradicionales guerras o enfrentamientos bélicos entre Estados. Es el caso de las catástrofes naturales como resultado del deterioro del medio ambiente. La Resolución Resolución 70/1 incide en este aspecto en la que los Estados ahondan y afirman las amenazas que la escasez de agua o alimentos así como el uso irresponsable de las tecnologías pueden entrañar para la paz y la seguridad internacionales. La paz es tanto la base para el diseño de nuevas estrategias por parte de los Estados como el medio para hacer viable los Objetivos contemplados en la Agenda 2030.

Baste observar que las protestas populares que se producen en diversos contextos del mundo coinciden en ser canales de expresión de indignación individual contra un sistema que, en lugar de impulsar la construcción de sociedades inclusivas, se desarrolla movido por nociones que, al fin y al cabo, lo que generan es exclusión: nacionalismo, religión, raza, género, 
etnia. De ahí que para la próxima década cabe vaticinar una creciente demanda por el reconocimiento de la identidad y la dignidad que implicará importantes desafíos para las democracias constitucionales: ¿Cómo (re)configurar o (re)crear instituciones políticas para hacer frente a la crisis de representatividad? ¿Cómo (re)formular modelos económicos que propicien la reducción de las desigualdades y el desarrollo sostenible? La década de 2020 a 2030 será seguramente un tiempo de cambios relevantes en los que se profundizará en mutaciones políticas y sociales. Y no sólo obedecerá a un cambio de costumbres provocadas por las tecnologías de la comunicación y la inteligencia artificial sino también por mudanzas en las formas de organización política de las sociedades. En los próximos diez años habrá complejos desafíos para conciliar la protección de los derechos humanos, los ideales del constitucionalismo y la democracia con el de un desarrollo sostenible.

La crisis de la pandemia mundial que se está viviendo, derivada del Covid-19, ya ha puesto de manifiesto situaciones inéditas que han exigido la adopción de medidas extraordinarias no sólo en el ámbito sanitario sino también democrático, económico, social y jurídico. Los efectos del Covid-19 han acabado afectando, de una manera u otra, a todos los ODS. En el caso del ODS 16, aquellas poblaciones más vulnerables o en situaciones de guerra y escenarios de conflicto, han sido golpeadas más duramente por el virus. La crisis económica que se cierne amenazante ha reducido las contribuciones de empresas y otros agentes a ayudas al desarrollo y a otros ámbitos por lo que, a pesar del esfuerzo realizado para que quienes desarrollan trabajos informales o en situación de vulnerabilidad estén sostenidos por el sistema, se verán reducidas frenando muchos de los procesos de inclusión que estaban en marcha. De ahí que, además de ser Objetivos, la paz, la justicia y las instituciones sólidas deben ser consideradas valores esenciales que inspiren la Agenda de transformaciones de la próxima década.

\section{REFERENCIAS BIBLIOGRÁFICAS}

Ara Pinilla, I. (1990). Las transformaciones de los derechos humanos, Madrid, Tecnos.

Barona Vilar, S. (2016). Justicia Integral” y Access to Justice. Crisis y evolución del "paradigma", en: Barona Vilar, S. (Editora), Mediación, Arbitraje y Jurisdicción en el actual paradigma de Justicia, Thomson Reuters-Civitas, Pamplona. p. 31 y ss.

Cacho Sánchez, Y. (2019): La Agenda 2030 para el desarrollo sostenible y el convenio europeo de derechos humanos: ¿la reforma de su sistema de protección podría incidir en la implementación del ODS 16 ("paz, justicia e instituciones sólidas")?, Revista Electrónica de Estudios Internacionales, 2019, pp.1-34. DOI: 10.17103/reei.37.04 
Díaz Galán, E. (2018). Paz y Objetivos de desarrollo sostenible: la contribución del Objetivo 16, en: DÍAZ BARRADO, C.M; FERNÁNDEZ LIESA, C.R. (Directores), D. M., VERDIALES LÓPEZ (Coordinadora), Objetivos de desarrollo sostenible y Derechos humanos: paz, justicia e instituciones sólidas/ derechos humanos y empresas, Universidad Carlos III de Madrid, pp. 249-264.

Gallopín, G. (2003). Sostenibilidad y desarrollo sostenible: un enfoque sistémico. Santiago de Chile, Naciones Unidas, 2003.

Jonas, H., [1979]. El principio de responsabilidad: Ensayo de una ética para la civilización tecnológica, Barcelona, Herder, 2004.

Ferrajoli, L. (2004). Razones jurídicas del pacifismo. Madrid, Trotta.

Ferrari, V. (1989). Funciones del derecho. Madrid, Editorial Debate.

Galtung, J. (1964). Editorial, Journal of Peace Research, vol. 1, nº 1, pp. 1-4.

Galtung, J. (1969). Violence, peace and peace research, Journal of Peace Research, vol. 6, $\mathrm{n}^{\mathbf{o}}$ 3, pp. 167-191.

Galtung, J. (1998). Tras la Violencia 3r: Reconstrucción, reconciliación, resolución. Afrontando los efectos visibles e invisibles de la guerra y la violencia. Bilbao. Gernika Gogoratuz.

García Villaluenga, 1. y Vázquez de Castro, E. (2020), Editorial. Impulso legislativo a la mediación, entre la incertidumbre y la esperanza, Anuario de Mediación y solución de conflictos 2018-2019. Madrid, Reus, pp.21-33.

Kelsen, H. (2017). La paz por medio del Derecho, $2^{\mathrm{a}}$ ed., Barcelona, Trotta.

Llano Alonso, F. H. (2002). El humanismo cosmopolita de Inmanuel Kant. Cuadernos "Bartolomé de las Casas", nº 25, Madrid, ed. Dykinson.

Mesa, M. (2017). "El Objetivo $\mathrm{n}^{\circ} 16$ de Desarrollo Sostenible: paz, seguridad y gobernanza", Temas para el debate, pp.17-30. <https://fundacionfomentohispania.org/ods-agenda-2030/>

Pérez Luño, A. E. (1991). La seguridad jurídica. Barcelona, Ariel.

Pérez Luño, A. E. (2006). Diez tesis sobre la titularidad de los derechos humanos, La tercera generación de Derechos humanos. Pamplona, Thompson Aranzadi, 2006, pp.229-242.

Pérez Sauceda, J. B. (2015). Ccultura de paz y resolución de conflictos: la importancia de la mediación en la construcción de un estado de paz, Ra Ximhai, vol. 11, núm. 1, Universidad Autónoma Indígena de México, enero-junio, pp. 109-131.

Quispe Remón, F (2018). “Acceso a la justicia y objetivos del desarrollo sostenible”, en: DÍAZ BARRADO, C.M; FERNÁNDEZ LIESA, C.R. (Directores), D. M., VERDIALES LÓPEZ (Coordinadora), Objetivos de desarrollo sostenible y Derechos humanos: paz, justicia 
e instituciones sólidas/ derechos humanos y empresas, Universidad Carlos III de Madrid, pp. 235-248.

Riechmann, J., "Sostenibilidad: algunas reflexiones básicas”, Ética y Filosofía Política, pp.116. https://www.upf.edu/materials/.../sossostenibilidadreflexiones.pd.

Robles, G. (Director) (2015). Documento de Trabajo 2015. Compromiso universal por un desarrollo humano y sostenible: posición española para la Agenda post2015. 20 enero de 2015. versión final. Secretaría General de Cooperación Internacional para el Desarrollo (MAEC), pp. 29-30.<www.aecid.es > Centro-Documentacion > Documentos>

Rodríguez Palop, Ma . E. (2006). El derecho a la paz: un cambio de paradigma, en: I. Campoy Cervera; J.L. Rey Pérez; Ma . E. Rodríguez Palop (Editores), Desafíos actuales a los Derechos humanos. Reflexiones sobre el derecho a la paz, Madrid, Dykinson, S.L.

Sanahuja, J.A. (2018). "Paz, seguridad y gobernanza: el ODS 16 y la Agenda 2030 de desarrollo sostenible", en: DÍAZ BARRADO, C.M; FERNÁNDEZ LIESA, C.R. (Directores), D. M., VERDIALES LÓPEZ (Coordinadora), Objetivos de desarrollo sostenible y Derechos humanos: paz, justicia e instituciones sólidas/ derechos humanos y empresas, Universidad Carlos III de Madrid, pp.26-56.

Soleto Muñoz, H., El derecho colaborativo como una nueva forma de resolución adecuada de conflictos, V/LEX España. https://libros-revistas-derecho.vlex.es/vid/derecho-colaborativonueva-forma-685513993

Striedinger Meléndez, P. (2016). Bioética y desarrollo sostenible, Rev. Pistis Prax., Teol. Pastor, Curitiba, v. 8, nº. 2, pp. 497-526.

Vega, J. (2014). La actualidad de la equidad de Aristóteles. Doce tesis antiformalistas sobre el derecho y la función Judicial, Cuadernos Electrónicos de Filosofía del Derecho, 29, pp.113144.

\section{PÁGINAS WEB}

Transformar nuestro mundo: Agenda 2030 para el Desarrollo Sostenible. Resolución aprobada por la Asamblea General de Naciones Unidas el 25 de septiembre de 2015. A/RES/70/1. http://www.un.org/sustainabledevelopment/es/2015/09/la-asamblea-general-adopta-laagenda-2030-para-el-desarrollo-sostenible/.

Informe de la Comisión Mundial sobre el Medio Ambiente y el Desarrollo: "Nuestro Futuro Común" (Our Common Future) -WCED-, agosto 1987, Oxford University Press, 1987. https://es.scribd.com/.../ONU-Informe-Brundtland-Ago-1987-Informe-de-la-Comisio

Declaración de Rio sobre el medio Ambiente y el Desarrollo, 1992, Naciones Unidas. Doc. A/CONF.151/26 (el Vol. Yo) (1992). www.unesco.org/education/pdf/RIO_S.PDF.

Real Decreto 419/2018, de 18 de junio. Informe de Gobernanza. Consejo de Ministros 15.02.19. Informe sobre los mecanismos e instrumentos de coordinación para la 
implementación de la Agenda 2030 en España. https://www.agenda2030.gob.es/.../INFORME_DE_GOBERNA;

Plan de Acción para la implementación de la Agenda 2030". Hacia una Agenda Española de Desarrollo Sostenible. Gobierno de España. (22 de junio de 2018). www.exteriores.gob.es/.../PLAN\%20DE\%20ACCION\%20PARA\%20LA\%20IMPLEME..

II Plan de Atención a la Diversidad (2017-2022)

https://www.educa.jcyl.es/dpburgos/es/apebu/inclusion-orientacion-educativa-absentismo

Agenda 2030. Ministerio de Asuntos Exteriores, Unión Europea y Cooperación http://www.exteriores.gob.es/Portal/es/PoliticaExteriorCooperacion/Agenda2030/Documents/ Informe\%20de\%20Progreso\%202019.pdf

Programa Mundial para la educación en Derechos Humanos. UNESCO. https://es.unesco.org/themes/programas-construir-paz

Red de Soluciones de Desarrollo Sostenible (SDSN). https://www.sdgindex.org/ .

Agencia Europea del Medio Ambiente (EEA) https://www.eea.europa.eu/soer2015/europe/consumption

Consulta Nacional - Financiación del Desarrollo Post2015 - Salamanca, 25 de marzo de 2015

$2^{\text {a }}$ Consulta Nacional - Posición Española Agenda Post2015: Avances y Retos - Madrid, 15 de septiembre de 2014. Posición Española para la Agenda Post2015 (.pdf)

Coordinadora de Organizaciones de cooperación para el desarrollo https://coordinadoraongd.org/2017/10/europa-cumplira-07-2052/

Ley 27/2005, de 30 de noviembre, de fomento de la educación y la cultura de la paz. https://www.boe.es > buscar > pdf > BOE-A-2005-19785-consolidado

Informe de los Objetivos de Desarrollo Sostenible (2017). Nueva York, Naciones Unidas, 2017.

ggim.un.org > TheSustainableDevelopmentGoalsReport2017_Spanish

Informe de los Objetivos de Desarrollo Sostenible (2018).

https://unstats.un.org/sdgs/files/report/2018/TheSustainableDevelopmentGoalsReport2018es.pdf

Informe de los Objetivos de Desarrollo Sostenible (2019).

https://unstats.un.org/sdgs/report/2019/The-Sustainable-Development-Goals-Report2019_Spanish.pdf

Progress towards the Sustainable Development Goals (2018-2019)

https://sustainabledevelopment.un.org/content/documents/22700E_2019_XXXX_Report_of_t he_SG_on_the_progress_towards_the_SDGs_Special_Edition.pdf

Reshaping governance for sustainability (2016-2019) 
https://www.2030spotlight.org/en/book/1883/chapter/reshaping-governance-sustainability

Las empresas españolas ante la Agenda 2030.

http://www.exteriores.gob.es/Portal/es/SalaDePrensa/Multimedia/Publicaciones/Documents/4 \%20Las\%20empresas\%20espa\%C3\%B1olas\%20ante\%201a\%20Agenda\%202030.pdf

Los Objetivos de Desarrollo Sostenible en 100 ciudades españolas (2018) http://reds-sdsn.es/wp-content/uploads/2018/10/Informe-urbano-REDS-ODS-2018-parte-I.pdf

La Comunitat Valenciana y la implementación de los ODS a nivel local http://localizingthesdgs.org/library/202/3/La-Comunitat-Valenciana-y-la-implementacin-delos-ODS-a-nivel-local-Una-Comunitat-comprometida-con-la-Cooperacin-y-la-Agenda-2030para-el-Desarrollo-Sostenible.pdf

Directrices de implementación de la Agenda 2030. Junta de Castilla y León.

https://www.jcyl.es/web/jcyl/AdministracionPublica/es/Plantilla100/1284836243978/_/__

ODS en Burgos. Ayuntamiento de Burgos

http://www.aytoburgos.es/tu-ciudad/ods-2030

Marco de indicadores mundiales para los Objetivos de Desarrollo Sostenible y metas de la Agenda 2030 para el Desarrollo Sostenible (División de Estadística de las Naciones Unidas) https://unstats.un.org/sdgs/indicators/Global\%20Indicator\%20Framework_A.RES.71.313\%20 Annex.Spanish.pdf

Indicadores de la Agenda 2030. Instituto Nacional de Estadística (INE).

https://www.ine.es/dynt3/ODS/es/index.htm

Organización de las Naciones Unidas para la Educación, la Ciencia y la Cultura http://es.unesco.org/

Mantenimiento de la Paz de las Naciones Unidas

http://www.un.org/es/peacekeeping/

Oficina del Alto Comisionado para los Derechos Humanos

http://www.ohchr.org/SP/pages/home.aspx

Mapa de Indicadores de la Agenda 2030 en España.

https://www.agenda2030.gob.es > sites $>$ default $>$ files $>$ recursos

Tabla ODS / Derechos humanos elaborada por ACNUDH

https://www.ohchr.org/Documents/Issues/MDGs/Post2015/SDG_HR_Table.pdf.

Trabalho recebido em 24 de junho de 2020

Aceito em 05 de julho de 2020 